\title{
Growing seismicity in the Sichuan Basin and its association with industrial activities
}

\author{
Xinglin $\mathrm{LEI}^{1^{*}}$, Jinrong $\mathrm{SU}^{2}$ \& Zhiwei $\mathrm{WANG}^{3}$ \\ ${ }^{1}$ Geological Survey of Japan, National Institute of Advanced Industrial Science and Technology (AIST), Higashi 1-1-1, \\ Tsukuba, Ibaraki 305-8567, Japan; \\ ${ }^{2}$ Earthquake Monitoring Centre, Sichuan Earthquake Administration, Chengdu 610041, China; \\ ${ }^{3}$ State Key Laboratory of Earthquake Dynamics, Institute of Geology, China Earthquake Administration, Beijing 100029, China
}

Received February 19, 2020; revised May 28, 2020; accepted June 22, 2020; published online September 22, 2020

\begin{abstract}
In the Sichuan Basin, seismic activity has been low historically, but in the past few decades, a series of moderate to strong earthquakes have occurred. Especially since 2015, earthquake activity has seen an unprecedented continuous growth trend, and the magnitude of events is increasing. Following the M5.7 Xingwen earthquake on 18 Dec. 2018, which was suggested to be induced by shale gas hydraulic fracturing, a swarm of earthquakes with a maximum magnitude up to M6.0 struck Changning and the surrounding counties. Questions arose about the possible involvement of industrial actions in these destructive events. In fact, underground fluid injection in salt mine fields has been occurring in the Sichuan Basin for more than 70 years. Disposal of wastewater in natural gas fields has also continued for about 40 years. Since 2008, injection for shale gas development in the southern Sichuan Basin has increased rapidly. The possible link between the increasing seismicity and increasing injection activity is an important issue. Although surrounded by seismically active zones to the southwest and northwest, the Sichuan Basin is a rather stable region with a wide range of geological settings. First, we present a brief review of earthquakes of magnitude 5 or higher since 1600 to obtain the long-term event rate and explore the possible link between the rapidly increasing trend of seismic activity and industrial injection activities in recent decades. Second, based on a review of previous research results, combined with the latest data, we describe a comprehensive analysis of the characteristics and occurrence conditions of natural and injection-induced major seismic clusters in the Sichuan Basin since 1700. Finally, we list some conclusions and insights, which provide a better understanding of why damaging events occur so that they can either be avoided or mitigated, point out scientific questions that need urgent research, and propose a general framework based on geomechanics for assessment and management of earthquake-related risks.
\end{abstract}

Keywords Induced seismicity, Fluid injection, Sichuan Basin, Shale gas, Wastewater disposal, Salt mine

Citation: Lei X, Su J, Wang Z. 2020. Growing seismicity in the Sichuan Basin and its association with industrial activities. Science China Earth Sciences, 63 (11): 1633-1660, https://doi.org/10.1007/s11430-020-9646-x

\section{Introduction}

Enhanced geothermal systems (EGSs), shale gas hydraulic fracturing (HF, also known as "fracking"), disposal of wastewater from resource extraction, and geological sequestration of $\mathrm{CO}_{2}$ and other waste fluids, play an important role in

\footnotetext{
* Corresponding author (email: xinglin-lei@aist.go.jp)
}

the mitigation of global warming. In these applications, fluids are intensively forced into deep formations or reservoirs. Fluid-injection-induced/triggered earthquakes have attracted growing attention, and injection activities for these applications must be adequately addressed for efficient and safe operation (e.g., Ahmad and Smith, 1988; Bachmann et al., 2011; Kanamori and Hauksson, 1992; Kerr, 2012; Kim et al., 2018; Langenbruch et al., 2020; Lei et al., 2008; Majer 
and Peterson, 2007; Yang et al., 2017).

The words "induced" and "triggered" are used almost in an equivalent manner in many scientific papers. In some papers, the term "induced" is used to include both cases (Ellsworth, 2013). The well-known (but not widely accepted) definitions are as follows. (1) An earthquake that releases anthropogenically induced stress is defined as induced; otherwise, the earthquake releases tectonic stress, and it is thus defined as triggered (McGarr et al., 2002). However, this definition is still having difficulty gaining universal acceptance, because noticeable ("felt") earthquakes mainly release tectonic stress. (2) Seismicity within the zone affected by the injection is termed as induced, and seismicity out of the zone, including a large earthquake initiated within the zone and ruptured beyond the zone, is triggered. For example the $M_{\mathrm{W}} 5.5$ Pohang, Korea, earthquake was designated as triggered by EGS stimulation (Ellsworth et al., 2019).

A neutral definition must consider the extent to which industrial activities advance or accelerate the occurrence time of a specific earthquake at the tectonic loading speed. The advanced time should be estimated from reliable simulation (see Section 6 for details). In areas such as the Sichuan Basin, where the tectonic loading speed is very small, a small amount of additional stress can greatly advance the occurrence time of a potential earthquake. Furthermore, without additional stress, the earthquake may never occur, and the tectonic stress will be released by slow deformation. Therefore, unless reliable simulation results indicate otherwise, this article uses the word "induced", although some cases may fall into the category of "triggered".

Injection-induced seismicity has been observed in different regions. There are many research results and thousands of academic papers on specific cases. Thus, it is helpful to promote integrated investigations in a region having different tectonic settings and injection patterns. In the Sichuan Basin of China, both long-term and short-term injections have caused felt induced seismicity, including some destructive earthquakes. Long-term injections continue for a few years to several tens of years for disposal of wastewater and mining of salt (Lei et al., 2013, 2008; Zhang et al., 2012). Short-term injections continue over several months at a well pad for shale gas HF (Lei et al., 2017a, 2019a; Meng et al., 2019; Tan et al., 2020). Similar to other sites (Atkinson et al., 2016), a high level of HF-induced seismicity and moderate magnitude earthquakes were limited to only some of the HF sites in the Sichuan Basin. Among several shale gas blocks in the Sichuan Basin, the Changning block demonstrated the highest level of induced seismicity (Figure 1). Following the M5.7 Xingwen earthquake on 18 Dec. 2018, which was suggested to be induced by shale gas HF (Lei et al., 2019a), an earthquake swarm with maximum magnitudes of M6.0 struck Changning and the surrounding counties (Lei et al., 2019b; Liu and Zahradník, 2020; Yi et al., 2019). In this article, $M$ indicates either the local magnitude $\left(M_{\mathrm{L}}\right)$ or surface wave magnitude $\left(M_{\mathrm{S}}\right)$, and the moment magnitude is denoted as $M_{\mathrm{W}}$. For the Sichuan Basin, $M_{\mathrm{W}}$ is normally smaller than $M_{\mathrm{S}}$ or $M_{\mathrm{L}}$. An increase in the magnitude and number of triggered events associated with fluid injection has led to a growing awareness of potential risks. This, coupled with its socio-economic significance, has led to a surge in scientific interest in high-frequency induced seismic activity. In applications that do not require HF, such as the storage of wastewater and well salt production, seismic activities are unnecessary but sometimes unavoidable. With regard to shale gas HF, the purpose is to create new fractures, widen existing fractures, or both to enhance the permeability of the reservoir and thus achieve economic gas production. Therefore, HF is accompanied by microseismic events, whose magnitude is usually $<0$ in shale gas sites of the Sichuan Basin (Chen et al., 2018). This kind of microseismicity, which is called "HF microseismicity" in this paper, does not cause harm, but is a useful proxy for the stimulated part of the reservoir (Mayerhofer et al., 2010).

Induced earthquakes mean that activation of pre-existing fault systems during HF may lead to larger felt earthquakes. Generally, shallow earthquakes with a magnitude of about 2 will be felt. In areas that have never experienced a strong earthquake historically, frequent earthquakes of $M 3$ to $M 4$ will cause some damage, and earthquakes of $M 5$ can cause serious damage. Of course, because there is no clear lower limit of magnitude for induced earthquakes, there is no strict boundary between HF microseismicity and induced earthquakes. Injection-induced seismic risk from low-probability and high-impact events is an emerging issue encountered by the rapidly increasing development of shale gas extraction in the southern Sichuan Basin. To ensure that injection operations can be carried out effectively and safely, destructive earthquakes must be either avoided or mitigated. Clarifying the mechanism and geomechanical conditions of induced earthquakes and predicting the maximum magnitude of a potential earthquake that might be induced at a given site are thus scientific challenges. In the Sichuan Basin, earthquakes induced by different types of injections under different geological conditions have been observed. Thus, lessons learned from this basin are helpful for both earthquake seismology and industrial applications.

The present paper presents a review with renewed data and results on seismicity within the Sichuan Basin with a focus on injection-induced earthquakes. First, we analyze earthquakes of magnitude 5 or higher since 1600 to obtain the long-term event rate and explore the possible link between the rapidly increasing trend of seismic activity and industrial injection activities in recent decades. Second, based on a review of previous research results, combined with some recent data and renewed results, we comprehensively analyze the characteristics and occurrence conditions of natural 


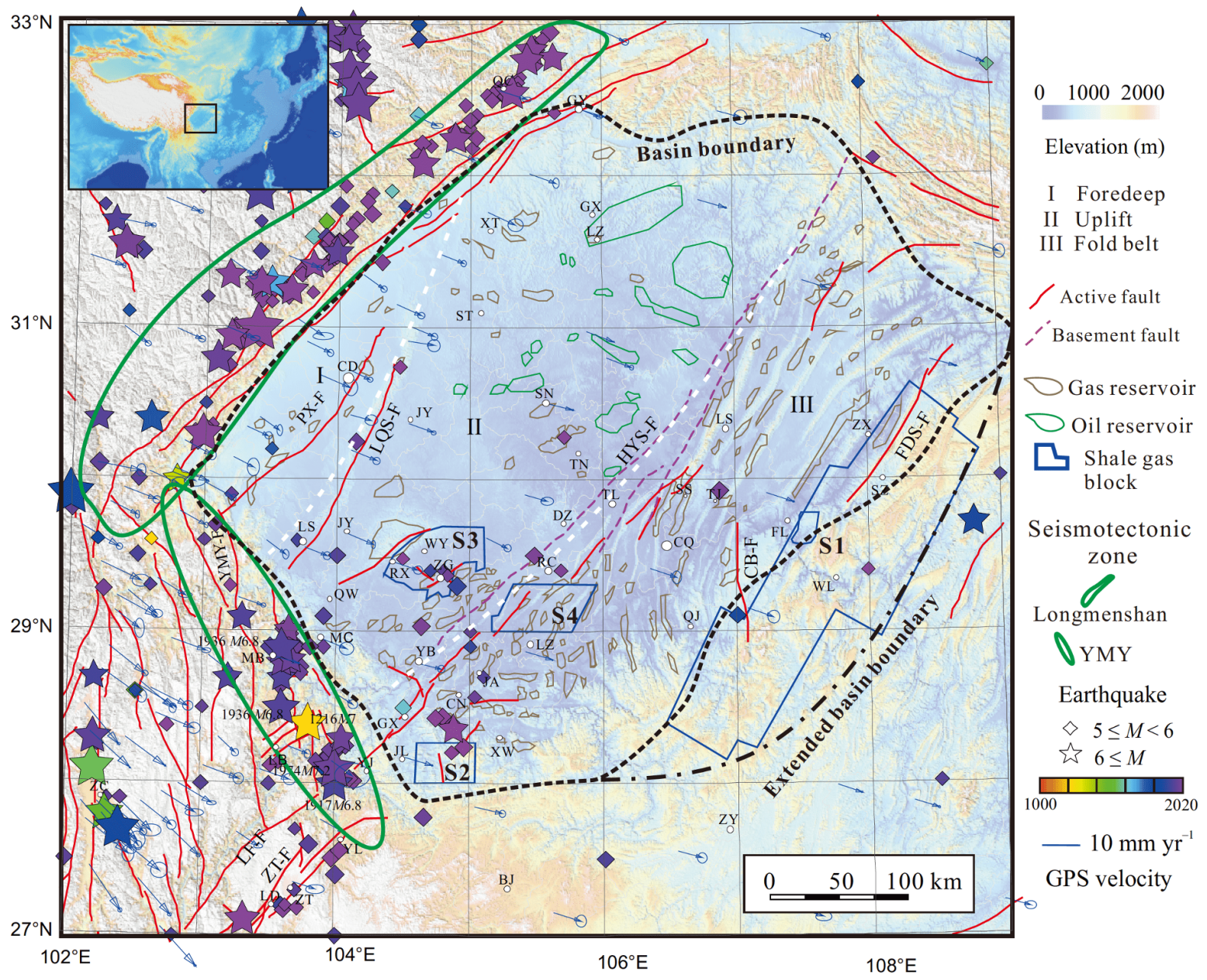

Figure 1 Map of active faults; major gas, oil, and shale gas reservoirs; and epicentral distribution of $M \geq 5$ earthquakes for the past 5 decades in the Sichuan Basin and surrounding areas. Fault data were imported from the digital "Map of active tectonics in China" (Deng et al., 2007). The oil and gas field outlines are modified from an open report (Ryder et al., 1994) and a paper (Zhao and Yang, 2015). Blue arrows show the interseismic GPS velocity field (Zheng et al., 2017). The background topography is based on the Shuttle Radar Topography Mission digital elevation model (http://srtm.csi.cgiar.org/SRTM3). The earthquake catalog data set was provided by the China Earthquake Data Center (http://data.earthquake.cn). Seismic features: CB-F, Changling-Banbianshan fault; FDS-F, Fangdoushan fault; LF-F, Lianfeng fault; LQS-F, Longquanshan fault; PX-F, Pujiang-Xinjin fault; YMY-F, Yingjing-Mabian-Yajin fault; ZT-F, Zhaotong fault; YMY, Yingjing-Mabian-Yajin seismotectonic zone. Counties: CN, Changning; FL, Fuling; GX, Gaoxian; LB, Leibo; LS, Leshan; MB, Mabian; QW, Qianwei; RC, Rongchang; RX, Rongxian; SN, Suining; TJ, Tongjing; TN, Tongnan; WL, Wulong; WY, Weiyuan; XW, Xingwen; YB, Yibin; YJ, Yanjin.

and injection-induced major seismic clusters in the Sichuan Basin. Finally, we list some insights gained from the Sichuan Basin, identify phenomena that remain poorly understood, and propose a general framework that uses geomechanics for assessment and management of earthquake-related risks.

\section{Geological setting and fault stability analysis}

\subsection{Geological setting}

The Sichuan Basin is located in southwestern China (Figures 1 and 2). To the west, the basin meets the tectonically active Tibetan Plateau, characterized by complex Cenozoic structures marked by intense deformation and high levels of seismic activity, including frequent large earthquakes. The Sichuan Basin has a protracted, two-stage tectonic history: early marine extensional, and later terrestrial compressive. The northwest boundary of the basin is very clear, corresponding to the Longmenshan thrust faults (Figures 1 and 2). The southwest boundary corresponds to the Yingjing-Mabian-Yanjin fault zone (YMY-F in Figure 1), which is dominated by left-lateral, strike-slip faulting. The north segment of the YMY fault zone has relatively weak seismic activity. The middle segment, centered on Mabian County, is characterized by earthquake swarms with magnitudes up to 6.8. The southern segment is characterized by strong earthquakes, with a maximum magnitude of 7.2.

In map view, the basin is characterized by three major structures: (1) a triangular northwestern depression on the northwest side, west of Longquan Mountains and centered on Chengdu Plain; (2) a northeast-trending central uplift zone of broad, gentle anticline and syncline structures; and 


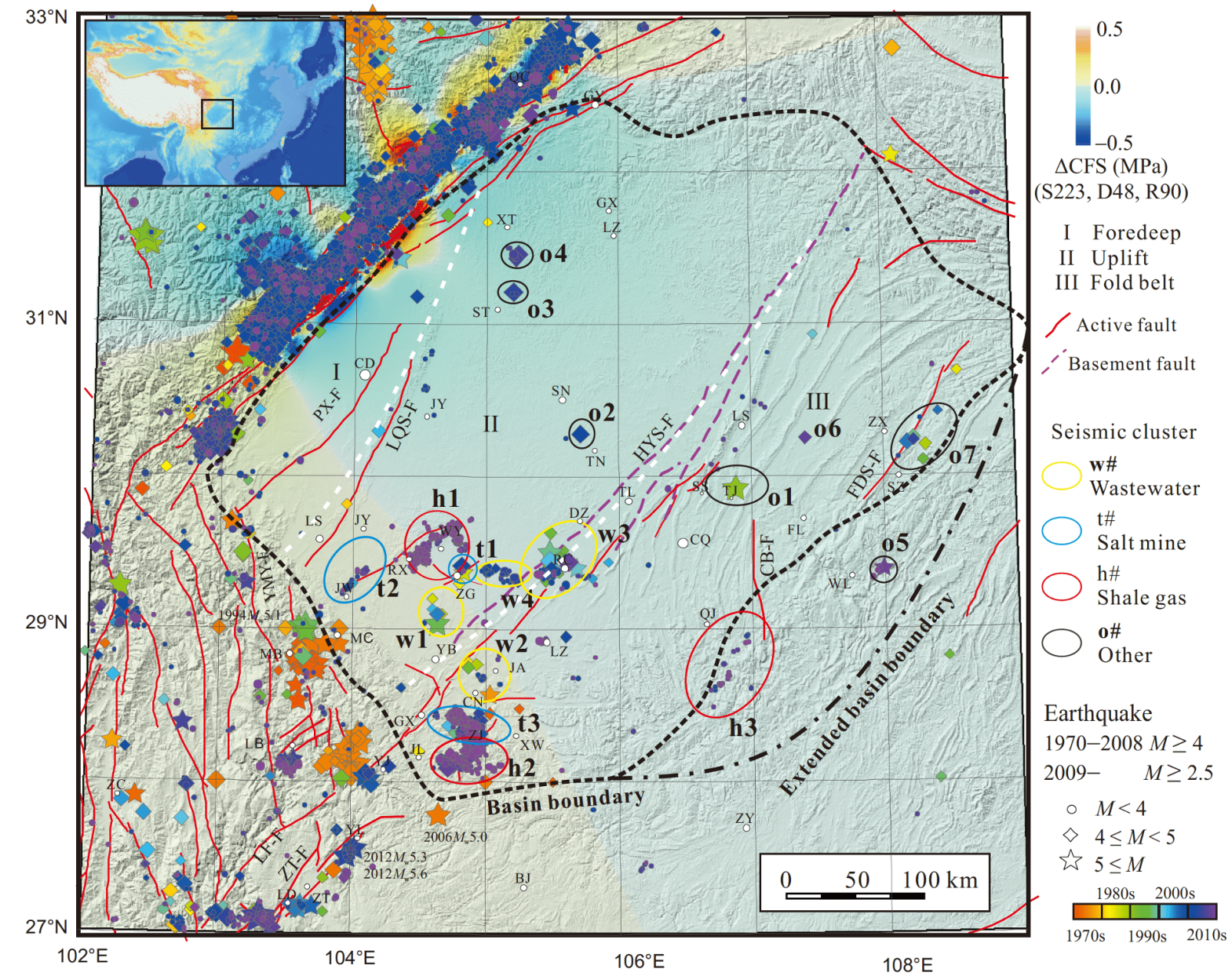

Figure 2 Map of active faults and major seismic clusters during the past 5 decades in the Sichuan Basin and surrounding areas. The background shading (as defined by the color bar at the upper right) shows the coseismic change of Coulomb failure stress ( $\triangle \mathrm{CFS}$ ) from the 2008 Wenchuan earthquake to northeaststriking reverse faults; strike/dip/rake $=223^{\circ} / 48^{\circ} / 90^{\circ}$. These were determined from a slip model that combined inversion of the teleseismic waveforms and the local seismic displacements (Wang et al., 2008). Figure S1 of the supplement (http://link.springer.com) is a similar map with a background color bar showing the distribution of volumetric strain. See the caption of Figure 1 for sources and abbreviations.

(3) a southeastern fold belt on the southeast side characterized by tight, predominantly northeast-southwest-strike narrow anticline and wide syncline structures, frequently associated with listric thrust faults at depth (cf. Korsch et al., 1991). The Longquan Mountains and Huaying Mountains are the boundaries of the three units. Vertically, it is characterized by two different units: sediment layers overlying a pre-Sinian crystalline basement. The upper unit is lightly deformed with flat folds, small-scale faults (most of them are blind), and widely distributed detachments at different depths along evaporite layers. The crystalline basement is characterized by strong metamorphic rocks. The top boundary of the basement is deeper in the northwest side and shallower in the southeast side, showing a gradual thinning from $\sim 13$ to $\sim 7 \mathrm{~km}$. In addition, some very large-scale basement structures are present, and they are believed to affect the overlying structures. The most important one is the northeast-trending Huayingshan reverse fault under the Huaying Mountains. As a result of the basin's multi-stage tectonic history, structures in the sedimentary formations show complicated patterns. New faults created during the uplift are favorably oriented for rupture under the presentday stress regime in this region. In contrast, old (and blind) faults normally show an unfavorable orientation.

In a broader context, the Sichuan Basin is located within the northwest portion of the stable South China block, has a strong crust and basement, and is referred to as a relatively stable continental region. GPS data show that the basin moves coherently with South China and has a very small present-day overall strain rate (Gan et al., 2007; Zheng et al., 2017), while the southern Sichuan Basin has a shear strain rate of (4-8) $\times 10^{-9} \mathrm{yr}^{-1}$ (Wang and Shen, 2020).

The Sichuan Basin is a large Paleozoic-Mesozoic-Cenozoic superimposed marine-terrestrial petroleum basin famous for rock salt and natural gas. At the same time, it is also one of the areas with the greatest potential for shale gas development in China. The production of well salt has a history over 2000 years long. The industrial exploration and 
development of natural gas also has continued for more than half a century. Well salt production with water injection has also been carried out for more than 70 years. Shale gas development, which started in 2008, has grown rapidly since 2015.

\subsection{Fault stability analysis}

As discussed above, a pre-existing fault is one of the necessary conditions for inducing significant earthquakes. It is thus necessary to introduce the basic theory about fault slip. In addition to the fault scale and density, the stress pattern and fault orientation are the most important factors in the Sichuan Basin and other areas of the world. Therefore, quantitative fault stability analysis is useful for risk assessment and management related to induced earthquakes (Streit and Hillis, 2004). Based on Coulomb's failure law, the critical condition for rupturing a pre-existing fault is

$\tau=\mu \sigma_{\mathrm{e}}=\mu\left(\sigma-P_{\mathrm{f}}\right)$,

where $\tau$ and $\sigma$ are shear and normal stresses acting on the fault plane, respectively; $P_{\mathrm{f}}$ is pore pressure; and $\mu$ is the sliding friction of the fault plane. A change in CFS ( $\triangle \mathrm{CFS})$ is defined as

$\Delta \mathrm{CFS}=\Delta \tau-\mu \Delta \sigma_{\mathrm{e}}$

The tendency of a planar discontinuous structure, such as a fault, to undergo slip under a given stress pattern depends on the frictional coefficient of the surface and the ratio of shear to normal stress acting on the plane. The slip tendency of the fault is defined as the ratio of the shear stress and normal stress (Morris et al., 1996) and thus equals the friction coefficient,

$T_{\mathrm{S}}=\tau / \sigma_{\mathrm{e}}$

$\Delta T_{\mathrm{S}}=\Delta \tau /(\Delta \sigma-\Delta P)$.

Slip-tendency analysis is a technique that visualizes the stress tensor in terms of its associated slip-tendency distribution and the relative likelihood and direction of slip on interfaces at all orientations (Morris et al., 1996). It can be used to assess the risks of injection. Under a uniform regional stress field, the most optimally oriented fault has the maximum slip tendency, as faults with greater slip tendency values rupture more easily.

Under the principal stress coordinate system $\left(s_{1}, s_{2}, s_{3}\right)$, the shear and normal stresses on a surface of given direction cosines $(l, m, n)$ can be calculated from the three principal stress magnitudes $\left(\sigma_{1}, \sigma_{2}\right.$, and $\sigma_{3}$ are the maximum, intermediate, and minimum principal stress magnitudes, respectively) as

$$
\begin{aligned}
\tau^{2}= & \left(\sigma_{1}-\sigma_{2}\right)^{2} l^{2} m^{2}+\left(\sigma_{2}-\sigma_{3}\right)^{2} m^{2} n^{2} \\
& +\left(\sigma_{3}-\sigma_{1}\right)^{2} n^{2} l^{2} \\
\sigma= & \sigma_{1} l^{2}+\sigma_{2} m^{2}+\sigma_{3} n^{2} .
\end{aligned}
$$

In many cases, the stress tensor is not fully defined, and only the direction of the principal stresses and the stress difference ratio $(R)$, or equivalently, the shape ratio $(\phi)$, are given (Etchecopar et al., 1981; Gephart and Forsyth, 1984),

$R=\frac{\left(\sigma_{1}-\sigma_{2}\right)}{\left(\sigma_{1}-\sigma_{3}\right)}$

$\phi=1-R=\frac{\left(\sigma_{2}-\sigma_{3}\right)}{\left(\sigma_{1}-\sigma_{3}\right)}$

Under a given regional stress field, the fault slip tendency is a function of the angle between the fault plane and the maximum principal stress axis. Generally, when this angle is around $30^{\circ}$ (for $\mu=0.6$ ) (optimally oriented or favorably oriented), the slip tendency is the largest and can be easily reactivated. The present-day stress field in a region is often controlled by active faults favorably oriented. As a result, unfavorably oriented faults are relatively stable. For the Sichuan Basin, it is reasonable to assume that the vertical stress is equal to the overburden pressure and the most favorable faults (virtual faults of the maximum slip tendency) are critically stressed. This is the worst-case assumption for induced earthquake risk assessment.

In addition to Coulomb's failure law, which determines whether a fault can slip or not, how the fault slips (seismic slip or creep) depends on the frictional constitutive properties of the fault. Once the fault starts to slide, its friction coefficient is related to the sliding speed and sliding history, and it changes dynamically. There are two kinds of frictional behavior: velocity (or slip) weakening and velocity (or slip) strengthening. Under a weakening condition, the steady state frictional stress decreases with an increase in sliding velocity, possibly leading to seismic slip. Under a strengthening condition, the steady state frictional stress increases with sliding velocity, and the resulting sliding is aseismic. The friction properties of shallow crustal faults of different maturity are also an important issue in induced seismicity research.

Figure 3 is a schematic diagram of the mechanism of injection-induced earthquakes and natural earthquakes driven by deep natural fluids in the Sichuan Basin. The slip tendency as a function of fault strike and dip angles in Figure $3 \mathrm{a}$ was calculated for stress patterns inverted using reliable mechanism solution data for three typical sites: (1) Luochang-Jianwu syncline, (2) Changning anticline, and (3) Weiyuan-Rongxian shale gas site and Rongchang wastewater disposal site. A critically or subcritically stressed fault can be activated by external stress (in the form of fault slip tendency) acting on the fault from different types of fluid injection and/or extraction. Earthquakes may be induced by increasing the slip tendency, which is related to stress pattern, fault position and orientation, and injection/extraction factors. 
(a) Luochang-Jianwu syncline

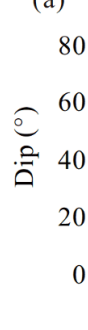

(b)
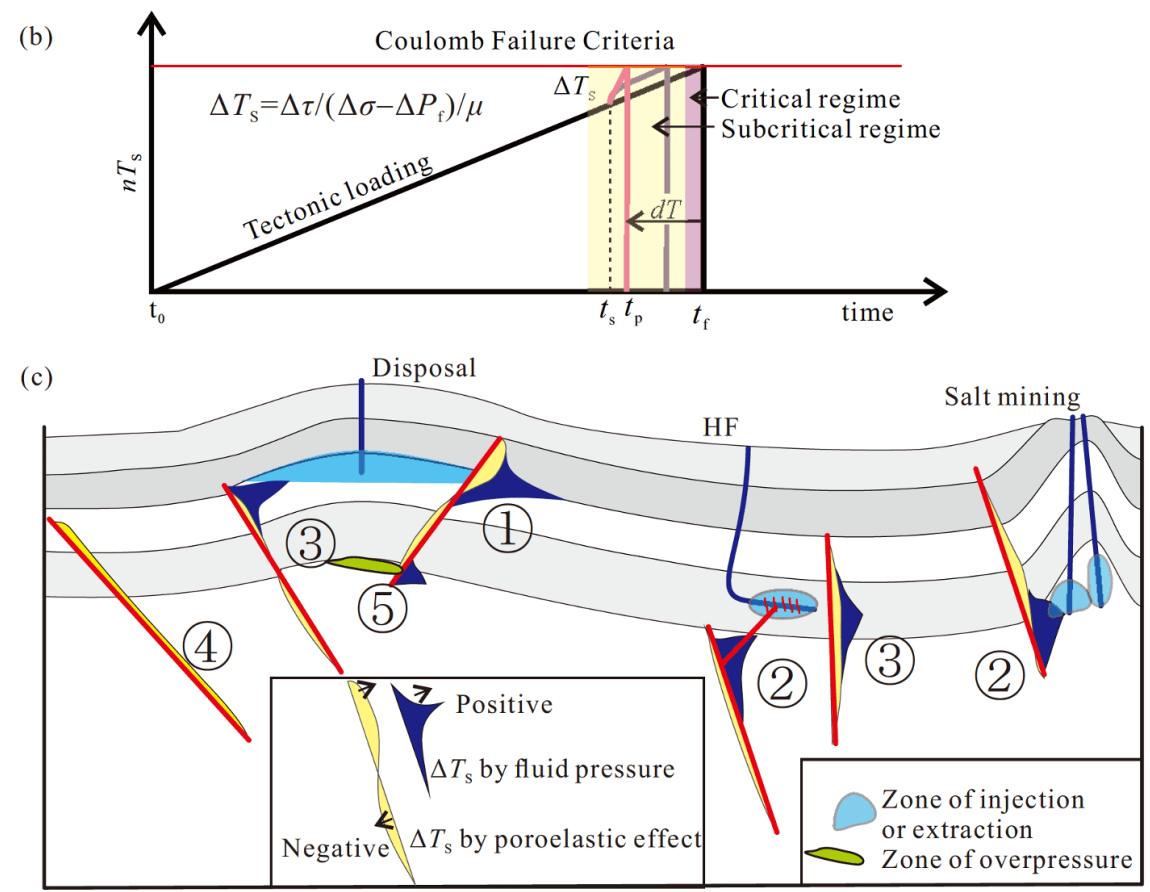

Figure 3 (a) Normalized slip tendency as a function of fault strike and dip for Luochang-Jianwu syncline, Changning anticline, and Weiyuan-Rongxian shale gas site. Faults with strike and dip falling into the red region have higher slip tendency under the estimated stress field. (b) Sketch plot showing the Coulomb failure criteria and the clock advance of earthquakes by external loading. The $t_{\mathrm{f}}$ is unperturbed time to failure, $t_{\mathrm{p}}$ is time to failure when external loading is considered, $t_{\mathrm{s}}$ is time of application of the external loading, $\mathrm{d} T=t_{\mathrm{f}}-t_{\mathrm{p}}$ is the clock advance, and $t_{0}$ is an arbitrary starting point. (c) Schematic diagram of external loading (in the form of fault slip tendency) acting on pre-existing faults from different types of fluid injection and/or extraction. Earthquakes may be induced by increasing the slip tendency, which is related to the stress pattern, fault position and orientation, and injection/extraction factors. (1), the fault passes through the reservoir zone, and fluid pressure plays a dominant role; (2), the fault connects with a zone with permeable channels; (3), the fault is close to the permeable zone, (4), the fault is far from the zone, and the poroelastic effect is dominant; (5), the fault connects overpressured reservoir or fluid pockets. Note that the external loading is inhomogeneous along the fault, and the poroelastic effect can lead to a higher or lower slip tendency.

\section{Major earthquakes within Sichuan Basin}

As compared with the northwest and southwest boundaries, the northeast and southeast boundaries of the Sichuan Basin are not as clear, and it is difficult to obtain a strict definition. In this article, as seen in Figure 1, based on previous studies (Korsch et al., 1991), we define the boundary of the basin so that the basin region covers all gas and oil fields and shale gas blocks. This article focuses on major seismic activity within the Sichuan Basin. Here, "major seismicity" indicates (1) spatially clustered earthquakes of many (>100) $M \geq 2$ events, (2) spatially clustered earthquakes of several $M \geq 4$ events, or (3) an earthquake sequence containing at least one $M \geq 5$ event. We also included several earthquakes on the northwest and southwest borders. Under its very low strain, it shows a lower degree of background seismicity; however, at least 36 events with a magnitude from 5.0 to 5.8 have been documented over the past 500 years.

\subsection{Major earthquakes of $M_{\mathrm{S}} \geq 5$}

Table 1 lists all $M_{\mathrm{S}} \geq 5$ earthquakes having an epicenter within the previously defined basin region since 1600 . In the Sichuan Basin, a $M_{\mathrm{S}} \geq 5$ earthquake must be strongly felt and result in heavy damage, even in the present day. In addition, unlike the surrounding areas, the Sichuan Basin has been relatively densely populated since ancient times, and thus, most past earthquakes are recorded in historical documents, 
such as local chronicles. In fact, many $M 4$ earthquakes were also documented (Editor-Group-of-Compiling-of-SichuanEarthquake-Data, 1980). Since the first seismic station at Beibei, Chongqing, was installed in the 1940s, most $M \geq 5$ earthquakes have been recorded. Therefore, as far as the interior of the basin is concerned, especially since 1600 , the catalog of earthquakes of $M \geq 5$ should be relatively complete. However, for historical earthquakes, the magnitude is inferred based on the degree of damage recorded in the literature, and its accuracy cannot be compared with that recorded by an instrument. However, it is not very difficult to delineate the tectonic location of moderate earthquakes and evaluate the frequency and characteristics of background seismic activity in the Sichuan Basin as a whole.

A summary of earthquakes occurring before 1940 is provided below. The location and magnitude of these earthquakes were estimated from information in historical documents (Editor-Group-of-Compiling-of-Sichuan-Earthquake-Data, 1980). More recent earthquakes are discussed in later sections.

(1) M5.5 Qingfu earthquake on 3 Feb. 1610, located in Qingfu Town of Gaoxian County (GX in Figure 2) at the southwest end of the Huayingshan fold mountain chain.

(2) M5 Pujiang earthquake in Mar. 1734. This event was located close to the Pujiang-Xinjing fault. Thus far, only two earthquakes are known to have occurred along the PujiangXinjing fault. The other one is the M5 Hongya earthquake on 1 July 1962, an event located at the southwest end of the fault.

(3) M5.5 Nanchuan earthquake on 24 Dec. 1854. According to the "Nanchuan County Chronicle" in the second year of Guangxu (1875), this earthquake was followed by felt aftershocks lasting about 1 year. The macroscopic epicenter was located at the intersection of the north-southstrike Changling-Banbianshan fault and some north-northeast-strike faults (Ding et al., 2004; Wang et al., 2009).

(4) M5 Nanxi earthquake on 12 Feb. 1892. Recently, a M4.3 earthquake occurred at almost the same place on 1 Jan. 2020. Moment tensor inversion of this event indicated reverse-dominated northeast or north-northeast-strike faulting. The centroid-moment-tensor (CMT) depth was very shallow, at about $2 \mathrm{~km}$. Strike/dip/rake of the FM1 and FM2 nodal planes are $155^{\circ} / 40^{\circ} / 55^{\circ}$ and $17^{\circ} / 58^{\circ} / 116^{\circ}$, respectively (Figure S1).

(5) M5.75 Fushun earthquake on 14 Feb. 1896. This earthquake, the largest earthquake in the Sichuan Basin before the 2019 Changning M6 earthquake, was felt over a wide area and was recorded in the chronicles of many counties. Following this earthquake, strongly felt aftershocks lasted more than 4 months, indicating a possible earthquake swarm.

(6) M5 Zigong earthquake on 9 Nov. 1905. Some felt foreshocks occurred 1 day before the largest shock, followed by some aftershocks. A M4.8 earthquake occurred on 22
May 1927 at the same site.

(7) M5 Lehan earthquake on 16 July 1913. This event was located in the south end of the Longquanshan fault zone.

(8) M5.5 Qianwei earthquake on 20 Dec. 1935. Followed by a strong aftershock after 3 minutes and another noticeable aftershock 10 hours later, this event resulted in heavy damage, including collapse of the Leshan City wall. It is interesting that a number of earthquakes with magnitudes up to 4.2 were induced by injections for salt mining in a nearby salt mine (see Section 3.3).

(9) M5.5 Muchuan earthquake on 16 May 1936. Located at the boundary of Qianwei and Muchuan counties, this event was probably an aftershock of the so-called Mabian earthquake sequence, which began with a main shock of M6.8 in Apr. 1936 along the north-south-strike Mabian-Muwen fault system. The M5.5 Qianwei earthquake was $30 \mathrm{~km}$ away from the Mabian-Muwen fault system, which is a very active structure with frequent occurrence of $M \sim 6$ earthquakes. A similar event, the M5.5 Muchuan earthquake on 29 June 1973, occurred $15 \mathrm{~km}$ south. Both events might have resulted from the rupture of unmapped faults in the basin region.

(10) M5.0 Jiang-an earthquake on 25 Sept. 1936. This earthquake was preceded by a few felt foreshocks (1 day before the main shock) and several aftershocks during the 3 days afterward.

\subsection{Natural origin earthquakes}

\subsection{1 $M_{S} 5.1$ Suining-Tongnan earthquake}

The $2010 M_{\mathrm{S}} 5.1$ Suining-Tongnan earthquake, which was located in the Moxi gas field, was a temporally and spatially isolated event ( 02 in Figure 2). A temporary station, which was installed $\sim 10$ hours later by the Chongqing Earthquake Administration, did not record any aftershocks. In agreement with the result of depth phases (Luo et al., 2011), the CMT depth was estimated to be approximately $2.8 \mathrm{~km}$, and thus the earthquake was nucleated in Triassic marine sediment, coincident with the depths of the top boundary of an overpressured gas reservoir (with a pressure ratio as high as $\sim 2.2$ ) in the Jialingjiang formation. The strike/dip/rake of the estimated source fault is $223^{\circ} / 48^{\circ} / 122^{\circ}$, showing a rupture area $\sim 2.4 \mathrm{~km}$ long along a blind reverse fault consistent with the geological structure and regional stress regime of this area. Through an integrated analysis, it was suggested that the associated fault slip of this earthquake was most probably initiated and driven by an episodic fluid flow from the underlying overpressured reservoir (or pockets) into the shallower gas reservoirs in production for many years through a fault-valve behavior (Lei et al., 2017b).

\subsection{2 $M_{S} 5.5$ Jitian earthquake and $M_{S} 5.1$ Qingbai-Jiang earthquake}

The Longquanshan Mountain range, which corresponds to 
Table 1 List of $M_{\mathrm{S}} \geq 5.0$ earthquakes within the Sichuan Basin ${ }^{\text {a) }}$

\begin{tabular}{|c|c|c|c|c|c|c|c|c|c|}
\hline No. & Date & Latitude & Longitude & $H(\mathrm{~km})$ & $H_{\mathrm{CMT}}(\mathrm{km})$ & $M_{\mathrm{S}}$ & $M_{\mathrm{W}}$ & Type & Place name or source \\
\hline 1 & $1610-02-03$ & $28.5^{\circ} \mathrm{N}$ & $104.5^{\circ} \mathrm{E}$ & & & 5.5 & & $\mathrm{O}$ & Gaoxian, Qingfu \\
\hline 2 & $1734-03-05$ & $30.2^{\circ} \mathrm{N}$ & $103.5^{\circ} \mathrm{E}$ & & & 5.0 & & $\mathrm{O}$ & Pujiang \\
\hline 3 & $1854-12-24$ & $29.1^{\circ} \mathrm{N}$ & $107.0^{\circ} \mathrm{E}$ & & & 5.5 & & $\mathrm{O}$ & Nanchuan Eq. \\
\hline 4 & $1892-02-10$ & $28.9^{\circ} \mathrm{N}$ & $105.0^{\circ} \mathrm{E}$ & & & 5.0 & & $\mathrm{O}$ & Nanxi \\
\hline 5 & $1896-02-14$ & $29.3^{\circ} \mathrm{N}$ & $104.9^{\circ} \mathrm{E}$ & & & 5.8 & & $\mathrm{O}$ & Fushun \\
\hline 6 & 1905-11-09 & $29.4^{\circ} \mathrm{N}$ & $104.7^{\circ} \mathrm{E}$ & & & 5.0 & & $\mathrm{O}$ & Ziliujing \\
\hline 7 & $1913-07-16$ & $29.6^{\circ} \mathrm{N}$ & $103.7^{\circ} \mathrm{E}$ & & & 5.0 & & $\mathrm{O}$ & Leshan \\
\hline 8 & $1935-12-20$ & $29.5^{\circ} \mathrm{N}$ & $104.0^{\circ} \mathrm{E}$ & & & 5.5 & & $\mathrm{O}$ & Qianwei \\
\hline 9 & $1936-05-16$ & $29.1^{\circ} \mathrm{N}$ & $103.9^{\circ} \mathrm{E}$ & & & 5.5 & & $\mathrm{O}$ & Qianwei \\
\hline 10 & $1936-09-25$ & $28.7^{\circ} \mathrm{N}$ & $105.1^{\circ} \mathrm{E}$ & & & 5.0 & & $\mathrm{O}$ & Jiang-an \\
\hline 11 & $1954-10-24$ & $29.4^{\circ} \mathrm{N}$ & $104.8^{\circ} \mathrm{E}$ & & & 5.0 & & S & Zigong \\
\hline 12 & $1959-11-13$ & $29.00^{\circ} \mathrm{N}$ & $105.00^{\circ} \mathrm{E}$ & & & 5.0 & & W? & Jiang-an, Nanxi \\
\hline 13 & $1962-07-01$ & $29.90^{\circ} \mathrm{N}$ & $103.20^{\circ} \mathrm{E}$ & & & 5.1 & & $\mathrm{O}$ & Hongya \\
\hline 14 & $1967-06-24$ & $30.25^{\circ} \mathrm{N}$ & $104.13^{\circ} \mathrm{E}$ & & & 5.5 & & $\mathrm{O}$ & Jitian \\
\hline 15 & $1973-06-29$ & $28.90^{\circ} \mathrm{N}$ & $103.90^{\circ} \mathrm{E}$ & & & 5.2 & & $\mathrm{O}$ & Muchuan \\
\hline 16 & $1975-12-04$ & $28.57^{\circ} \mathrm{N}$ & $105.03^{\circ} \mathrm{E}$ & & & 5.1 & & W? & Jiangan \\
\hline 17 & $1985-03-29$ & $29.37^{\circ} \mathrm{N}$ & $104.83^{\circ} \mathrm{E}$ & 7 & & 5.0 & & S & Zhang et al., 1993 \\
\hline 18 & $1989-11-20$ & $29.92^{\circ} \mathrm{N}$ & $106.88^{\circ} \mathrm{E}$ & 5 & & 5.2 & & OD & Ding et al., 2004 \\
\hline 19 & $1989-11-20$ & $29.92^{\circ} \mathrm{N}$ & $106.88^{\circ} \mathrm{E}$ & 5 & & 5.4 & & OD & Ding et al., 2004 \\
\hline 20 & $1996-02-28$ & $29.03^{\circ} \mathrm{N}$ & $104.63^{\circ} \mathrm{E}$ & & & 5.4 & & $\mathrm{~W}$ & Du et al., 2002 \\
\hline 21 & $1997-08-13$ & $29.50^{\circ} \mathrm{N}$ & $105.48^{\circ} \mathrm{E}$ & & & 5.6 & & $\mathrm{~W}$ & Lei et al., 2008 \\
\hline 22 & 1999-08-17 & $29.40^{\circ} \mathrm{N}$ & $105.68^{\circ} \mathrm{E}$ & & & 5.0 & & W & Lei et al., 2008 \\
\hline 23 & 2010-01-31 & $30.28^{\circ} \mathrm{N}$ & $105.71^{\circ} \mathrm{E}$ & & 2.8 & 5.1 & & OD & Lei et al., 2017 \\
\hline 24 & $2017-01-28$ & $28.09^{\circ} \mathrm{N}$ & $104.72^{\circ} \mathrm{E}$ & & 1.8 & 5.0 & 4.67 & $\mathrm{~F}$ & Lei et al., 2019a \\
\hline 25 & $2017-11-23$ & $29.39^{\circ} \mathrm{N}$ & $107.99^{\circ} \mathrm{E}$ & & & 5.0 & & OD? & This study \\
\hline 26 & $2018-12-16$ & $28.24^{\circ} \mathrm{N}$ & $104.95^{\circ} \mathrm{E}$ & & 3 & 5.7 & 5.17 & $\mathrm{~F}$ & Lei et al., 2019a \\
\hline 27 & 2019-01-03 & $28.20^{\circ} \mathrm{N}$ & $104.86^{\circ} \mathrm{E}$ & & 1.8 & 5.3 & 4.82 & $\mathrm{~F}$ & Lei et al., 2019a \\
\hline 28 & $2019-02-25$ & $29.48^{\circ} \mathrm{N}$ & $104.49^{\circ} \mathrm{E}$ & & 1.7 & 5.0 & 4.54 & $\mathrm{~F}$ & \\
\hline 29 & 2019-06-17 & $28.36^{\circ} \mathrm{N}$ & $104.89^{\circ} \mathrm{E}$ & & 3.3 & 6.1 & 5.69 & $\mathrm{~S}$ & Lei et al., $2019 b$ \\
\hline 30 & 2019-06-17 & $28.42^{\circ} \mathrm{N}$ & $104.80^{\circ} \mathrm{E}$ & & 2 & 5.4 & 5.01 & $\mathrm{~S}^{*}$ & Aftershock \\
\hline 31 & $2019-06-18$ & $28.39^{\circ} \mathrm{N}$ & $104.88^{\circ} \mathrm{E}$ & & 4.8 & 5.4 & 4.82 & $\mathrm{~S}^{*}$ & Aftershock \\
\hline 32 & 2019-06-22 & $28.44^{\circ} \mathrm{N}$ & $104.79^{\circ} \mathrm{E}$ & & 1.6 & 5.6 & 5.05 & $\mathrm{~S}^{*}$ & Aftershock \\
\hline 33 & 2019-07-04 & $28.43^{\circ} \mathrm{N}$ & $104.74^{\circ} \mathrm{E}$ & & 7.6 & 5.6 & 5.05 & $\mathrm{~S}^{*}$ & Aftershock \\
\hline 34 & 2019-09-08 & $29.58^{\circ} \mathrm{N}$ & $104.82^{\circ} \mathrm{E}$ & & 2.4 & 5.4 & 4.99 & $\mathrm{~F}$ & This study \\
\hline 35 & 2019-12-19 & $29.59^{\circ} \mathrm{N}$ & $104.82^{\circ} \mathrm{E}$ & & 2.58 & 5.2 & 4.73 & $\mathrm{~F}$ & This study \\
\hline 36 & $2020-02-03$ & $30.74^{\circ} \mathrm{N}$ & $104.46^{\circ} \mathrm{E}$ & & & 5.1 & & OD? & This study \\
\hline
\end{tabular}

a) The possible type of each earthquake is indicated as F (induced by hydraulic fracking), S (induced by salt mining), W (induced by disposal of wastewater), O (natural origin), or OD (natural origin related to deep natural fluid). ?, indicates that there is a greater uncertainty in the type assignment. *, indicates that the corresponding earthquake is an aftershock in the Changning M6 earthquake swarm and its type is indirect

the Longquanshan anticline and runs from Zhongjiang County in the north to Leshan in the south, is the boundary between the western Sichuan Plain and the central Sichuan Hills (LMS-F in Figures 1 and 2). A number of faults with a strike of $20^{\circ}-30^{\circ}$ northeast are distributed along the mountain range ( $\mathrm{Li}$ et al., 2013). On 24 Jan. 1967, a $M_{\mathrm{S}} 5.5$ earthquake with a focal depth of $\sim 4 \mathrm{~km}$ occurred, and it is the largest earthquake recorded in the Longquanshan fault zone since seismic stations were installed in 1958 (Xu et al., 2006). The M5 Lehan earthquake on 16 July 1913 was located at the south end of the Longquanshan fault zone, as aforementioned (Figure 2). On 2 Feb. 2020, an isolated $M_{\mathrm{S}} 5.1$ earthquake occurred in the northern section of the fault zone (Figure 2). The moment tensor inversion result shows that the depth was $3.3 \mathrm{~km}$, and the strike/dip/rake of the two nodal planes were $205^{\circ} / 54^{\circ} / 96^{\circ}$ and $15^{\circ} / 36^{\circ} / 82^{\circ}$, 
respectively. According to interferometric synthetic aperture radar (InSAR) data (to be published in a later paper), the nodal plane with a dip angle of $54^{\circ}$ may be the source fault. In addition to these $M 5$ earthquakes, historical documents have recorded 17 felt earthquakes, and there have been 6 M4-M4.9 earthquakes since 1958 (Xu et al., 2006). Therefore, the Longquanshan fault zone is relatively active within the Sichuan Basin. In fact, there are obvious radon anomalies along the faults (Liu et al., 2019). Many tunnels crossing the Longquan Mountain have encountered problems due to abnormally high gas concentrations (Su et al., 2014), and leakage of natural gas to the surface has been observed at several sites, indicating that some parts of these faults are leakage channels for deep fluids (mainly natural gas) and fluid flow is a possible driver of seismicity here.

\subsubsection{Tongjing $M_{S} 5.2$ and $M_{S} 5.4$ earthquake sequence}

On 9 Sept. 1989, a M3.7 earthquake followed by a M3.8 event only 2 minutes later occurred in the Tongjing area, which is located in the southeast fold zones of the Sichuan Basin (o1 in Figure 2). Two months later, two earthquakes having magnitudes of M5.2 and M5.4 occurred consecutively, also within 2 minutes of each other. In fact, small earthquakes had been felt since 13 Feb. 1989, and then a seismic station, the Tongjing station, was installed. Before and after these major events, more than $2700 M \geq 0.6$ fore- or aftershocks were observed with a maximum magnitude of 2.9. The seismograms recorded by the Tongjing station showed that that most events were concentrated within a very narrow space at a depth of $\sim 5 \mathrm{~km}$. The seismic hazard intensity map and focal mechanism show that these earthquakes were caused by reverse faults in the southeastern wing of the northeast-extending Tongluo gorge anticline (Ding et al., 2004). It is interesting that a large number of hot springs appeared after the earthquake. The source of the hot springs is the Jialingiiang limestone aquifer of the Lower Triassic with a burial depth of about $2.5 \mathrm{~km}$. There were some hot springs before the earthquake, but the number and scale were not as large. Similar to the 2008 Suining-Tongnan isolated earthquake, the Tongjing sequence could be also driven by fluid flow from overpressured reservoirs through fault-valve mechanisms. The difference is that the source and supply of fluid are much richer here, which not only triggers earthquake series but also stimulates hot spring activities that continue to the present. There is also a natural gas field nearby, but no data show whether there is any correlation between natural gas production and the Tongjing earthquake sequence.

\subsubsection{M5 Wulong earthquake on 23 Nov. 2017}

On 23 Nov. 2017, a M5 earthquake occurred in the Wulong District, Chongqing (05 in Figure 2). It can be also termed as an isolated earthquake because it was followed by few aftershocks with a magnitude less than 2.5. Seismicity in this area began in the summer of 2011 (Figure 4), coincident with the impoundment of the Yinpan Dam reservoir, which has a capacity of $3.2 \times 10^{8} \mathrm{~m}^{3}$. Although there is a seismic station a few kilometers away, no seismic activity was observed until 2011, so it is reasonable to assume that the seismicity before the $M 5$ earthquake was related to the impoundment of the reservoir water. The moment tensor obtained using the generalized cut and paste (gCAP) method (Zhu and BenZion, 2013) showed a normal faulting mechanism with a pure double-couple component and CMT depth of $9.4 \mathrm{~km}$ (Figure S2), in agreement with the routinely determined focal depth of $10 \mathrm{~km}$. The main shock was probably due to natural causes, while a role of the reservoir in triggering the event cannot be ruled out.

\subsection{5 $M_{W} 4.1$ Dianjiang earthquake on 11 Aug. 2016}

On 11 Aug. 2016, a $M_{\mathrm{W}} 4.1$ event occurred in Dian-jiang District, Chongqing (o6 in Figure 2). Seismological and geodetic evidence supports a thrust focal mechanism with a centroid depth of $\sim 1 \mathrm{~km}$. The strike/dip/rake of the source fault is $97^{\circ} / 45^{\circ} / 87^{\circ}$. It was suggested that this shallow earthquake was triggered by unloading from small-scale infrastructure construction just above a blind reverse fault being critically loaded by compressional stress (Qian et al., 2019).

\subsubsection{Seismicity along south segment of Fangdoushan fault}

The south segment of the Fangdoushan fault is probably the most active fault in the southeast fold zone of the Sichuan Basin (FDS-F in Figures 1 and 2). Medium and small earthquakes have been frequently observed. Since 1965, seven earthquakes of $M \geq 4$ have occurred, including a $M 4.6$ event on 21 Nov. 2004 and M4.2 event on 11 Feb. 2005. The mechanism solution of the M4.3 earthquake on 13 July 2013 showed a thrust fault of strike $/ \mathrm{dip} / \mathrm{rake}=24^{\circ} / 36^{\circ} / 81^{\circ}$ with a centroid depth of $4.4 \mathrm{~km}$ (Guo et al., 2014). Such a fault source is favorably oriented and thus critically stressed under the present-day stress regime here.

In addition to the six cases discussed above, two seismic clusters consisting of a few events of $M>4$ occurred in the north part of the central uplift area ( 03 and 04 in Figure 2). Both clusters are located close to some gas fields, and further study is required to determine whether these clusters were related to gas production or fluid injection.

\subsection{Earthquakes associated with long-term injection for salt mining}

\subsubsection{Ziliujing M4.6-M5.0 earthquakes}

The geological structure of the Ziliujing (which means artesian well in Chinese) anticline ( $\mathrm{t} 1$ in Figure 2) and the 

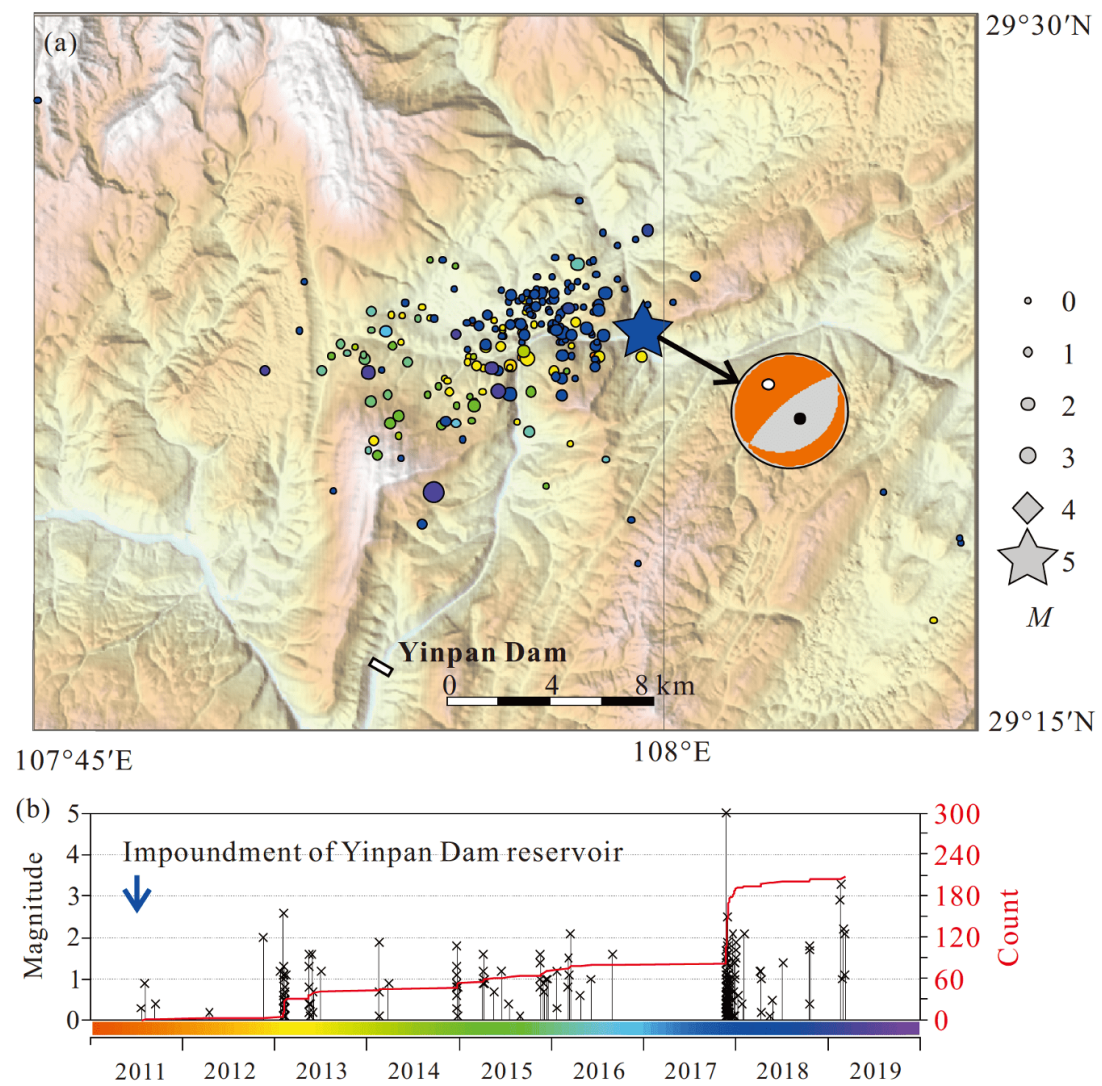

Figure 4 (a) Earthquake epicenters in the Wulong area overlaid on a digital elevation map, (b) magnitude and cumulative number (red curve) of $M \geq 0$ earthquakes over time from 2011 to 30 Aug. 2019. Seismicity in this area began after impoundment of the Yinpan Dam reservoir.

epicenters of strong earthquakes in this area are shown in Figure 5. The rocks exposed on the anticline are mainly Jurassic. The anticline axis extends along the $\mathrm{N} 60^{\circ} \mathrm{E}$ direction. The southwestern section of the anticline is cut by the Huanggepo fault. The southeast wing of the anticline has a set of blind faults showing a strike parallel to the anticline axis and a dip angle of $\sim 50^{\circ}$ toward the northwest. These faults cut through the Jurassic to the deep Ordovician rock formations at a depth of $4-5 \mathrm{~km}$. The west wing of the anticline also has hidden reverse faults, but they are not as developed as in the southeast wing.

The Dashanpu rock salt mine is located in the southeastern wing of the northeastern part of the Ziliujing anticline. Single-well convection mining began in 1967. More than a dozen wells have been drilled in succession. Some wells were horizontally docked in the late 1980s, and the annual production of brine reached more than $3 \times 10^{6} \mathrm{~m}^{3}$. In general, fresh water is injected at pressure about $7 \mathrm{MPa}$ for salt mining. Since 1947, five earthquakes with a magnitude ranging from 4.6 to 5.0 occurred beneath the Ziliujing anticline. Because these earthquakes caused abnormally heavy damage, the focal depths were assumed to be shallow. These earthquakes were $M 4.8$ on 10 Oct. 2008, M5.0 on 29 Mar. 1985, M5.0 on 24 Oct. 1954, and M4.8 on 17 Oct. 1947. The M5.0 event in 1985 was located in a region where significant water loss occurred and thus was considered to result from the reactivation of a blind reverse fault due to water injection (Zhang et al., 1993). Regarding the 1954 and 1965 earthquakes, the epicenter was located in the blind fault zone beneath the Daan salt mine, another important well salt mine southwest of the Dashanpu mine (Figure 5). During this period, water injection was carried out at the Daan salt mine. Therefore, the 1954 and 1965 earthquakes were also considered to be induced by water injection. Thus, since 1947, major earthquakes in the Ziliujing anticline may have been induced by injection. In the Ziliujing anticline, the most recent major earthquake was the $M 4.8$ event on 10 Oct. 2008, which occurred very close to the 1954 and 1965 earthquakes.

It is worth noting that the M5.75 Fushun earthquake on 14 Feb. 1896 was located about $10 \mathrm{~km}$ south of the Ziliujing anticline (Figure 5).

\subsubsection{Seismicity in Shuanghe salt mine area}

The Shuanghe salt mine is located in Shuanghe ancient town, Changning County ( $\mathrm{t} 3$ in Figure 2). The major rock salt body is bounded by dolomite of the Dengying formation and has a mean depth of $2800 \mathrm{~m}$ from the surface. Geologically, the mine is located in the Changning anticline, which has complicated structures with faults of different orientations and dip angles. During the period from 1970 to 1989, some 

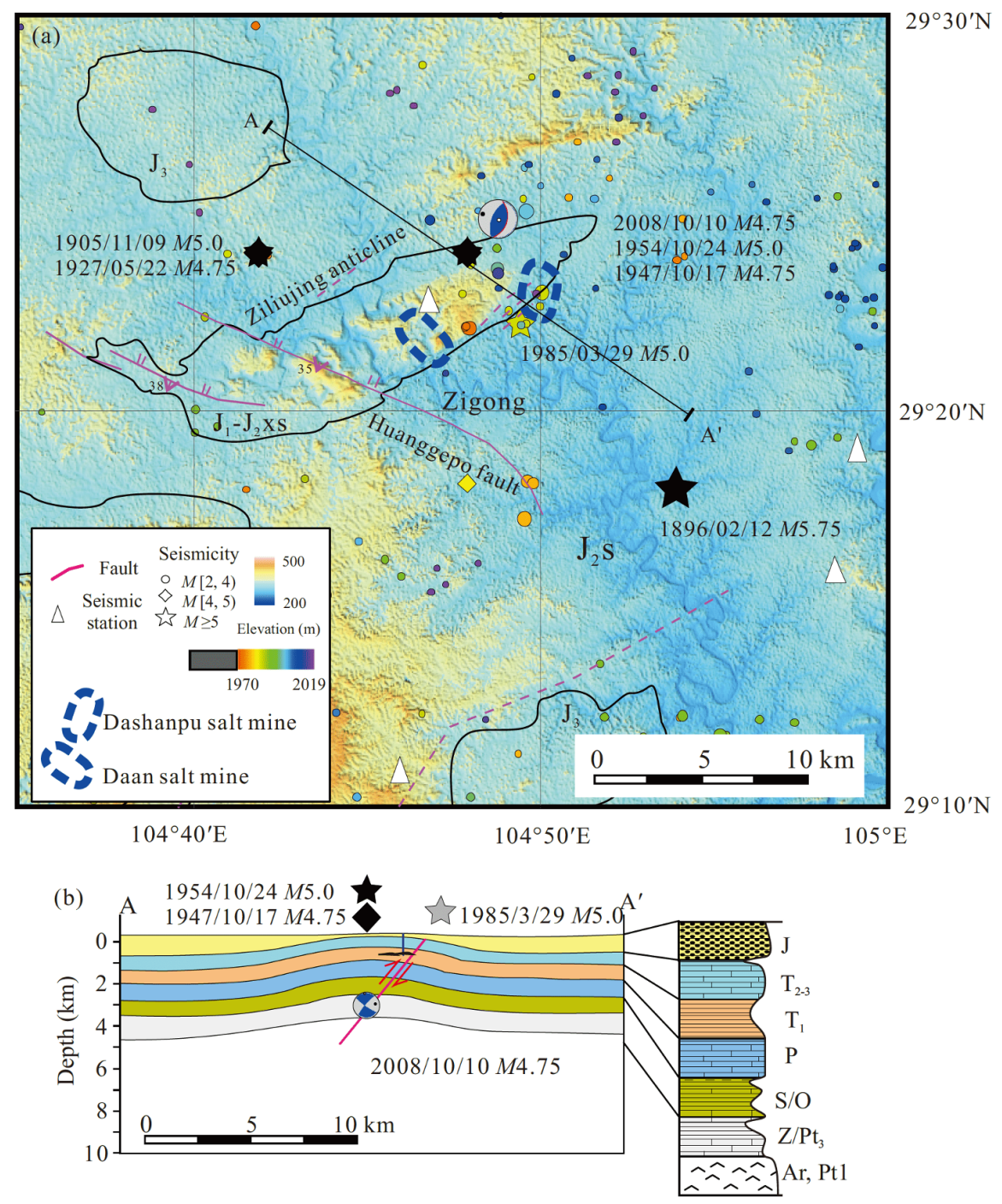

Figure 5 (a) Map of major structures and earthquake epicenters observed in the Ziliujing anticline and surrounding areas, (b) simplified geological section overlaid with hypocenters of major earthquakes. The focal mechanism of the M4.8 10 Oct. 2008 earthquake is shown with the lower-hemisphere projection of focal spheres viewed from the vertical profile. The focal depths of other earthquakes are not well constrained and are thus plotted at the top of the section.

earthquakes of $M<4$ were observed. These earthquakes, perhaps representing background activities, may be also related to the installation of the Ning-2 well, which was drilled in 1970-1971 for oil/gas prospecting. Even if it is assumed that these seismic events represent the background seismic levels in the area, an increase in seismic rate and an increase in maximum magnitude since the early 1990s are also evident.

Since the end of the 1980s, fresh water has been extensively injected through several deep wells with a depth of $2700-3000 \mathrm{~m}$ at a pressure of $8-10 \mathrm{MPa}$ for salt mining. After the start of injection, especially after the start of crosswell injection and production through horizontal docking, the event rate and the maximum magnitude demonstrated an increasing tendency. Increasing seismicity is clearly correlated with the injection history and water loss in the salt mine, indicating that earthquakes occurring before the M6 sequence were induced by long-term deep well injection (Lei et al., 2019b; Ruan et al., 2008; Sun et al., 2017).

In the middle of the night on 17 June 2019, a M6 earthquake occurred in Shuanghe Town. This event, which is the largest earthquake recorded within the Sichuan Basin (Lei et al., 2019b; Yi et al., 2019), was followed by a series of M4$M 5$ earthquakes over the next few days, showing the features typical of an earthquake swarm. The epicenter of the $M 6$ Changning earthquake was located within the well salt mine area, had a focal depth of 4-5 km (CMT depth of $3.3 \mathrm{~km}$ ), and is thus a potential case of injection-induced earthquake (Lei et al., 2019b). A later study suggested that the earthquake was initiated at $\sim 4 \mathrm{~km}$ along a thrust fault, then jumped to a near-vertical strike-slip fault (Liu and Zahradník, 2020). 
Ten reliable focal mechanism solutions for earthquakes of $M_{\mathrm{W}}>4$ were used to estimate the directions of three principal stress axes, stress shape ratio $\left(\phi=\left(\sigma_{2}-\sigma_{3}\right) /\left(\sigma_{1}-\sigma_{3}\right)\right)$, and pore pressure required to reactivate the source faults. The direction of the maximum principal stress axis was clearly resolved and was almost horizontal (plunge of $6.2^{\circ} \pm 4.4^{\circ}$ ) with an azimuth of $77^{\circ}$. The intermediate principal stress axis is also almost horizontal, and the minimum principal stress axis is nearly vertical. The obtained stress shape ratio was $\phi=0.4$ with a standard error of 0.15 . Under such a stress regime, reverse faults striking along the northwest and southeast directions have the maximum slip tendency and can be reactivated preferentially. The estimated overpressure ranged from 0.1 to $67 \mathrm{MPa}$. Five of 10 events showed an overpressure of less than $10 \mathrm{MPa}$, which could be explained by the long-term deep well injection because the maximum injection pressure is $\sim 10 \mathrm{MPa}$. For other earthquakes having a deeper focal depth or unfavorable fault orientation and dip angle, a reasonable interpretation requires other factors (Lei et al., 2019b).

As a result of long-term high-pressure water injection, the rock salt cavity is becoming increasingly larger, and the dolomite layer surrounding the salt formation could be connected with the highly pressurized water through direct exposure and some permeable fault zones. Because faults in brittle rocks are known to be highly permeable zones, the overpressured water can flow out along pre-existing faults and play a role in weakening the associated faults. As the water pressure increased and diffused, an increasing number of faults with different orientations reached a critical state, providing conditions for the occurrence of the Changing earthquake swarm (Lei et al., 2019b).

\subsubsection{Earthquake sequence in Luocheng and Changshan salt mine area}

In Changshan (located in Rong County) and Luocheng (Qianwei County), salt mines in the Changshan-Luocheng anticline (t2 in Figures 2 and 6) began production in the early 1970s. Coincident with water injection in these salt mines at a depth of more than $1000 \mathrm{~m}$, seismicity increased in this area. The largest event was the M4.2 earthquake that occurred on 15 Sept. 1979 (Lv et al., 2009). Later, after a dam was constructed in the area, additional earthquakes, which were thought to be impoundment-induced, were observed in the first several years after completion (1992-1995), with a maximum magnitude of 3.5 (Figure 6). Because of the continuous injection for salt production, felt earthquakes have continued to occur intermittently. Thus far, four earthquakes of $M \geq 4$ have been observed, including the latest M4.0 event in 2016 (Lv et al., 2009). Note that the Qianwei M5.5 earthquake that occurred on 20 Nov. 1935 (see Section 3.1) was located in the north part of the cluster (Figure 6a), indicating that this area is critically stressed and thus sensi- tive to water injection.

\subsection{Earthquakes associated with long-term injection for disposal of wastewater}

\subsubsection{Kongtan M5.4 earthquake sequence}

The Kongtan anticline (w1 in Figure 2) is a wide anticline extending about $30 \mathrm{~km}$ along the northeast direction. It is the trapping structure of natural gas reservoirs in this area (Figure 7). Since 1980, the Kong-12 well has been used to inject unwanted water into a Permian limestone formation at a depth $2.6 \mathrm{~km}$ from the surface (Du et al., 2002). The daily injection rate is generally in the range of $200-600 \mathrm{~m}^{3}$. The maximum well head pressure was $10.84 \mathrm{MPa}$. On $20 \mathrm{Feb}$. 1985, a M4.1 earthquake, located close to the injection well, was observed and caught the attention of the local earthquake department. Due to the lack of nearby seismic stations, small earthquakes could not be recorded, and the exact initiation time of seismicity associated with the injection is unclear. After the M4.1 earthquake occurred, several portable stations were installed. In total, six $M \geq 4$ earthquakes were observed. The largest event was the M5.4 earthquake on 28 Feb. 1996. Seismicity faded out at the end of 2008. No surface faults were mapped in the epicenter area of the M5.4 event. However, seismic exploration data confirmed that a group of blind thrust faults were developed in the Triassic and Permian formations, with a depth reaching about $3 \mathrm{~km}$ below the surface and a length up to $6 \mathrm{~km}$ (Du et al., 2002). These faults have a strike parallel with the anticline. As indicated by the damage distribution and focal mechanism solution, the largest event resulted from reactivation of one of the blind faults. Due to the spatial and temporal correlation between the seismicity and injection wells, this sequence of earthquakes was suggested to be induced by injection for wastewater disposal (Du et al., 2002).

\subsubsection{Earthquakes in boundary area of Jiang-an, Nanxi, Yibin, and Changning counties}

Earthquakes observed in the boundary area of Jiang-an, Nanxi, Yibin, and Changning counties (w2 in Figure 2) were probably linked to injection of wastewater. During the period from 1981 through 1992, significant seismicity was observed, including one M4.5 event in 1981 and two M4.2 events in 1987 and 1991. A recent seismically active period had events with magnitudes up to 3.2 from 2008 to 2012 . This area contains six gas reservoirs and gas-bearing structures. No documents have been published for these events. Among the 35 production wells, 15 wells also produced water at the rate of $150000 \mathrm{~m}^{3} \mathrm{yr}^{-1}$. Well Fujiamiao-8 (Fu\#8) produced gas since Oct. 1966 and has been used as an injection well since 1978. Since 2002, in addition, wells Chang\#11, Fu\#6, Lao\#5, and Mou\#20 have also been used for disposal (China Oil and Gas Field Development 

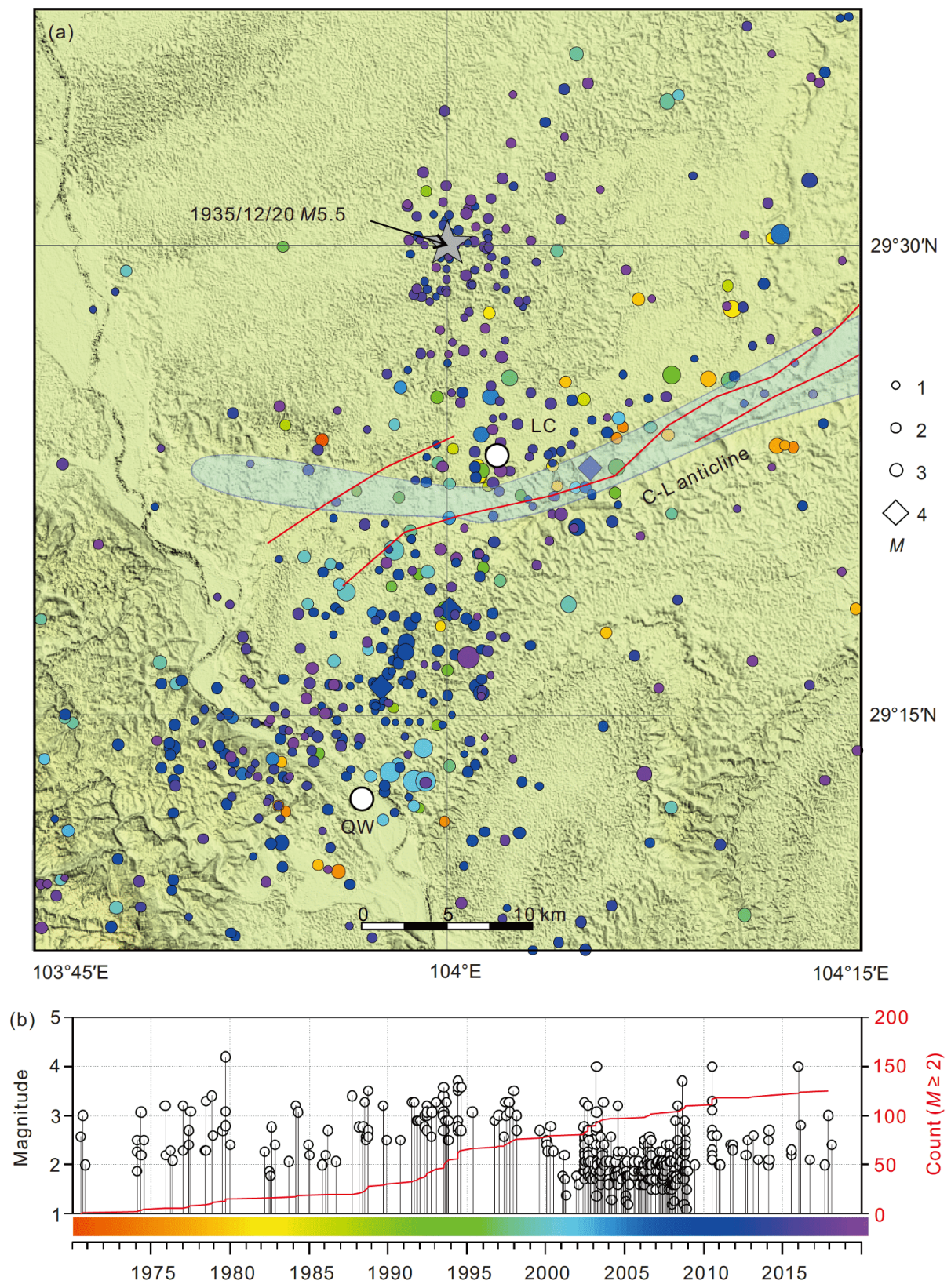

Figure 6 (a) Map of the Changshan-Luocheng (C-L) anticline, its major faults, and earthquake epicenters observed since 1970 in Luocheng (LC) and Qianwei (QW) districts, in which injection for salt production began in 1970, (b) magnitude and accumulated number of $M \geq 2.0$ earthquakes against time.

Chronicle Compilation Committee, 2011). Due to insufficient data, the link between these events and injections is not clear. From Feb. 2008 through 2009, $63700 \mathrm{~m}^{3}$ of water produced from Mou\#14 has been forced into the reservoir through Mou\#20, which might be responsible for the nearby seismicity that began in 2008 . The estimated total capacity is huge ( $8800000 \mathrm{~m}^{3}$ for Fu\#8 alone) and thus these wells could be in use for a long time. Unwanted water from shale gas wells in the Weiyuan-Rongxian demonstration block was transported and disposed of through these wells. Thus, this site deserves continued attention. In this area, a M5.1 event on 4 Dec. 1975 and M5 event on 25 Sept. 1936 are con- sidered to be natural in origin, indicating that critically stressed faults have the potential to produce earthquakes of M5 class.

\subsubsection{Induced earthquakes in Rongchang gas field}

The Rongchang earthquake cluster (w3 in Figure 2) is a wellknown case of injection-induced seismicity in China. In this area, injection of unwanted water on a routine basis began on 1 July 1978 and lasted for more than 3 decades. Unwanted water, collected from nearby production wells, was pumped into Permian formations at a depth of $\sim 3 \mathrm{~km}$ through several deep wells. During the period from 1978 through 2006, more 

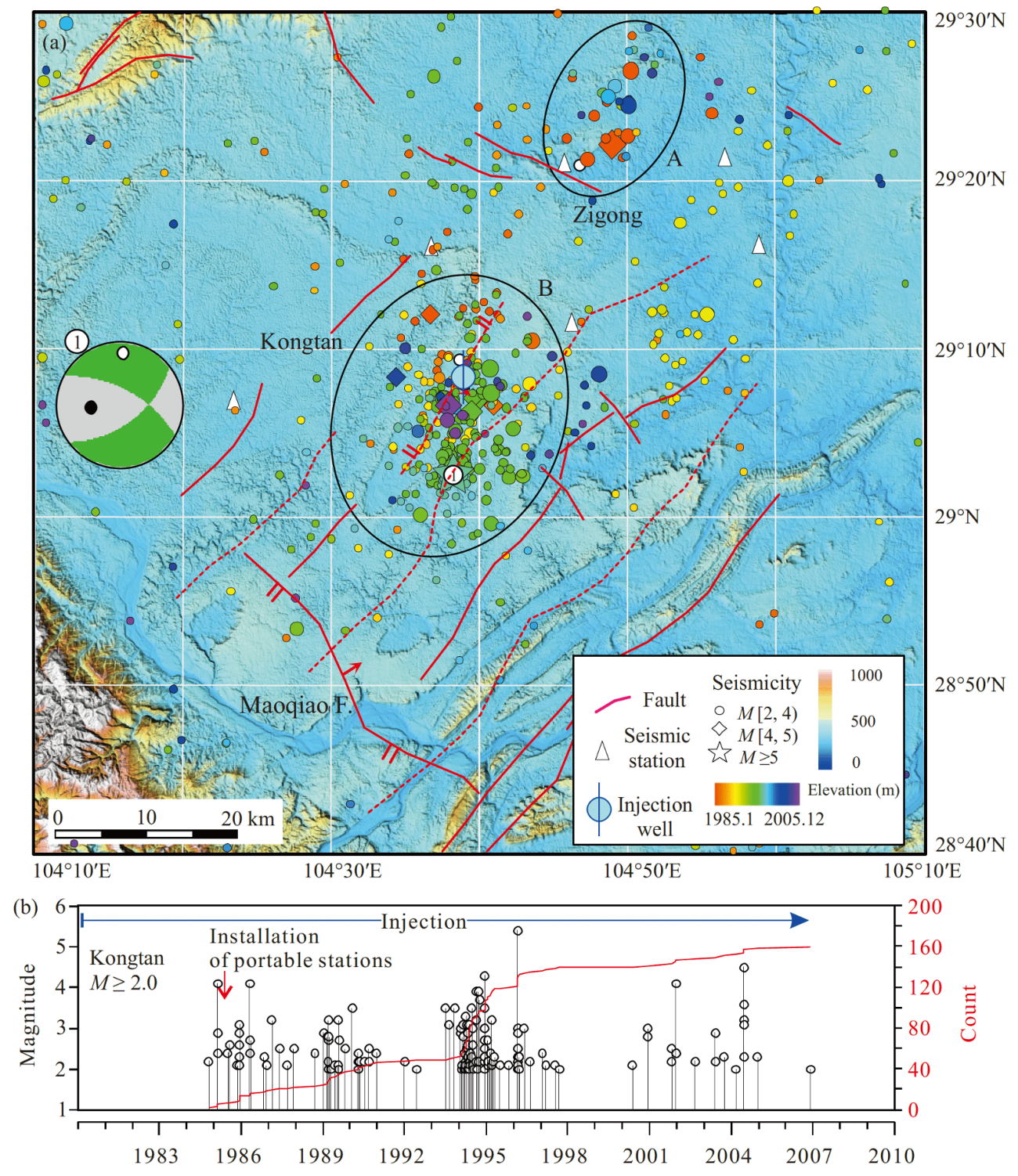

Figure 7 (a) Map of seismic stations, major structures, a disposal well, and earthquake epicenters observed from 1980 to 2010 in the Kongtan gas field and surrounding areas, (b) magnitude and cumulative number of $M \geq 2.0$ earthquakes over time, overlaid with the time window of injections.

than 20000 surface-recorded earthquakes, ranging up to M5.2, occurred (Lei et al., 2008). Injection data for this period are available, and the link between injections and seismicity is clear. A portable network of five stations was installed in late 2008 under a cooperative project between the Chongqing Earthquake Administration and Geological Survey of Japan. By the end of 2012, more than 2000 $M \geq 0.5$ events, including a $M 4.6$ earthquake occurring on 16 Oct. 2009, have been recorded (Wang et al., 2018) (Figure 8). Earthquake hypocenters demonstrate a fairly clear triggering front that can be represented by a reasonable hydraulic diffusion coefficient $\left(\sim 0.5 \mathrm{~m}^{2} \mathrm{~s}^{-1}\right)$ (Figure 9$)$. On 1 July 2001, injection at a major well (Luo-4) was stopped because (1) a correlation was suggested between the well and damaging earthquakes close to the well and (2) injec- tion pressure had reached the limits of the pumps used. Later, other nearby injection wells were also closed. Seismicity since 2008 was suggested to be related with injections at wells Bao\#11 and Bao\#24 (Wei and Liu, 2014). After closure of all nearby injection wells in 2013, seismicity decreased clearly, as expected. However, the event rate rose again since the end of 2016, and, on 27 Dec. 2016, a M4.9 earthquake occurred, followed by a $M 4.0$ event on the next day. Since then, seismicity kept a relatively high level. If we focus on earthquakes of $M \geq 2.5$, the event rate shows no significant changes (Figure 9c). Very interesting, small earthquakes have a clear and rapid response to the stop of water injection, but larger earthquakes show significant sustained activity. It is worth mentioning that the shale gas development in the north and south of the area has 
begun. The acceleration of seismic activity in recent years may be caused by hydraulic fracturing. Therefore, the future trend of seismic activity in the area deserves continuous attention.

The same method used for the Shangluo shale gas site (Lei et al., 2019a) and 12 focal mechanism solutions for earthquakes of $M_{\mathrm{W}}>3.5$ were used to estimate the regional stress pattern (to be published in a later paper). The maximum and intermediate principal stress axes are almost horizontal, while the minimum principal stress axis is nearly vertical. The maximum principal stress axis has a plunge of $2.6^{\circ} \pm 1.7^{\circ}$ and an azimuth of $120^{\circ}$. The obtained stress shape ratio was $0.94 \pm 0.03$. In such a stress regime, reverse faults of any strike direction could be easily reactivated (Figure 3a).

\subsubsection{Induced earthquakes in Huangjiachang gas field, Zigong}

Injection at deep well Jia\#33 in Huangjiachang gas field (w4 in Figure 2), located east of Zigong City, is a recent case of significant induced seismicity, and thus it was well documented (Lei et al., 2013; Zhang et al., 2012). The gas reservoir is associated with the Niufodu-Putaisi anticline structure, which shows an axis direction of N80E with the northwest-strike Niufodu fault. Well Jia\#33 is a depleted production well, and since 2007, it has been used for injection of unwanted water into the reservoir in the Makou formation, at a depth of $\sim 2500 \mathrm{~m}$. The Makou limestone/ dolomite formation of the Permian contains well-developed fractures. Injection at this site began in 2007, but no pumping was required until the end of 2008. During this early stage, only a few earthquakes with a magnitude less than 2.5 were observed. During the period of injection under high pressure from 2009 through $2010,130000 \mathrm{~m}^{3}$ of water was injected and more than $7000 M_{\mathrm{L}} 0.5+$ earthquakes occurred. The earthquake occurrence rate increased rapidly when the wellhead pressure exceeded $2 \mathrm{MPa}$ at the end of January 2009. The 16 Feb. 2009 M4.4 and 22 May 2009 M4.2 events, which mark the largest events of the earthquake sequence, were felt over a wide area, and minor damage was reported at sites near the epicenter. Event rates are clearly correlated with injection rates. Injection was shut down after July 2010, and seismicity tapered off rapidly (Lei et al., 2013).

A map view shows that the hypocenters migrated to concentrate in a narrow zone approximately $6 \mathrm{~km}$ long extending north-northwest and $2 \mathrm{~km}$ wide and centered approximately on the injection well. The hypocenter distribution is consistent with the west side of the NiufoduPutaisi anticline tip. A hypocenter density map demonstrates that the hypocenters are likely controlled by a set of preexisting conjugate fractures. Such fractures are consistent with the anticline structure and the regional stress field. In section views, more than $90 \%$ of hypocenters fall in the depth range of $2.5-4 \mathrm{~km}$, which corresponds to the Permian limestone formations. Shale and mudstone in the overlying and underlying layers act as a fluid diffusion barrier and play a role in arresting fractures in the limestone. At the hypocenter front, seismic activity was probably bounded by dipping faults, leading to upward and downward migrations (Lei et al., 2013).

\subsection{Earthquakes associated with short-term injection for shale gas-Shangluo site}

The Shangluo shale gas block (also referred as the Changning demonstration shale gas block) is located in the fold zone of the south boundary of the Sichuan Basin (h2 in Figure 2). This block corresponds to the Luochang-Jianwu flat syncline (surrounded by narrow anticlines), and the target Silurian mudstone/shale formation has a burial depth of less than $2 \mathrm{~km}$ to more than $3 \mathrm{~km}$. Vertical wells have been drilled there for shale gas prospecting since 2008. Drilling and fracturing of horizontal wells for evaluation purposes began in 2010, and systematic HF operations in horizontal wells for production of shale gas began in Dec. 2014 (Lei et al., 2017a; Lei et al., 2019a; Tan et al., 2020). Coinciding with these milestones, the observed seismicity in the region increased dramatically. Thus far, $10 M \geq 4.0$ earthquakes have been observed, including $4 M \geq 5.0$ earthquakes. The largest event of M5.7 on 16 Dec. 2018 was abnormally destructive, with a maximum hazard level of VII. Surface damage indicated that the Xingwen M5.7 earthquake faulting was probably nucleated within the zone of elevated pore pressure and unidirectionally ruptured northward several kilometers beyond the zone (Lei et al., 2019a).

Eighteen reliable focal mechanism solutions for earthquakes of $M_{\mathrm{W}}>3.5$ were used to estimate the directions of three principal stress axes, stress shape ratio, and pore pressure required to reactivate the source faults. The direction of the maximum principal stress axis was clearly resolved and was almost horizontal (plunge of $5.7^{\circ} \pm 3.3^{\circ}$ ) with an azimuth of $117^{\circ}$. The intermediate principal stress axis is also almost horizontal, and the minimum principal stress axis is nearly vertical. The obtained stress shape ratio was $\phi=0.15$ with a standard error of 0.08 . Under such a stress field, both strike-slip and reverse faults of a favorable orientation can be easily reactivated (Figure 3a). A CFS increment of $0.2-3.5 \mathrm{MPa}$ or an overpressure of $0.3-5.8 \mathrm{MPa}$ was necessary to cause these $M_{\mathrm{W}}>3.5$ earthquakes. Direct pore pressure effects are thought to be a necessary condition, at least for the largest out-of-zone events. Their source faults were unfavorably orientated (due to stress rotation after their formation) and thus required an additional CFS, which is greater than the load that the poroelastic effect could produce (Lei et al., 2019a). 


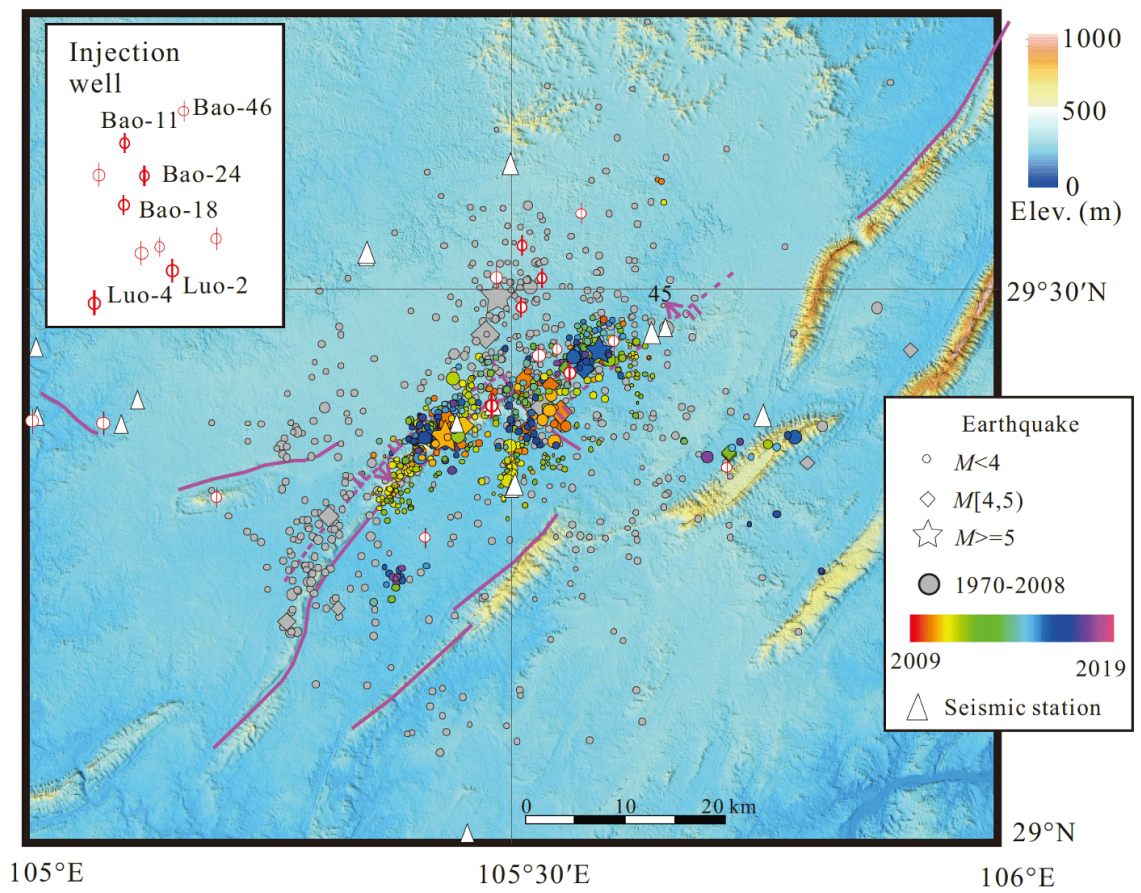

Figure 8 Map of seismic stations, major structures, disposal wells, and earthquake epicenters observed from 1970 to 2019 in the Rongchang gas field and surrounding areas.
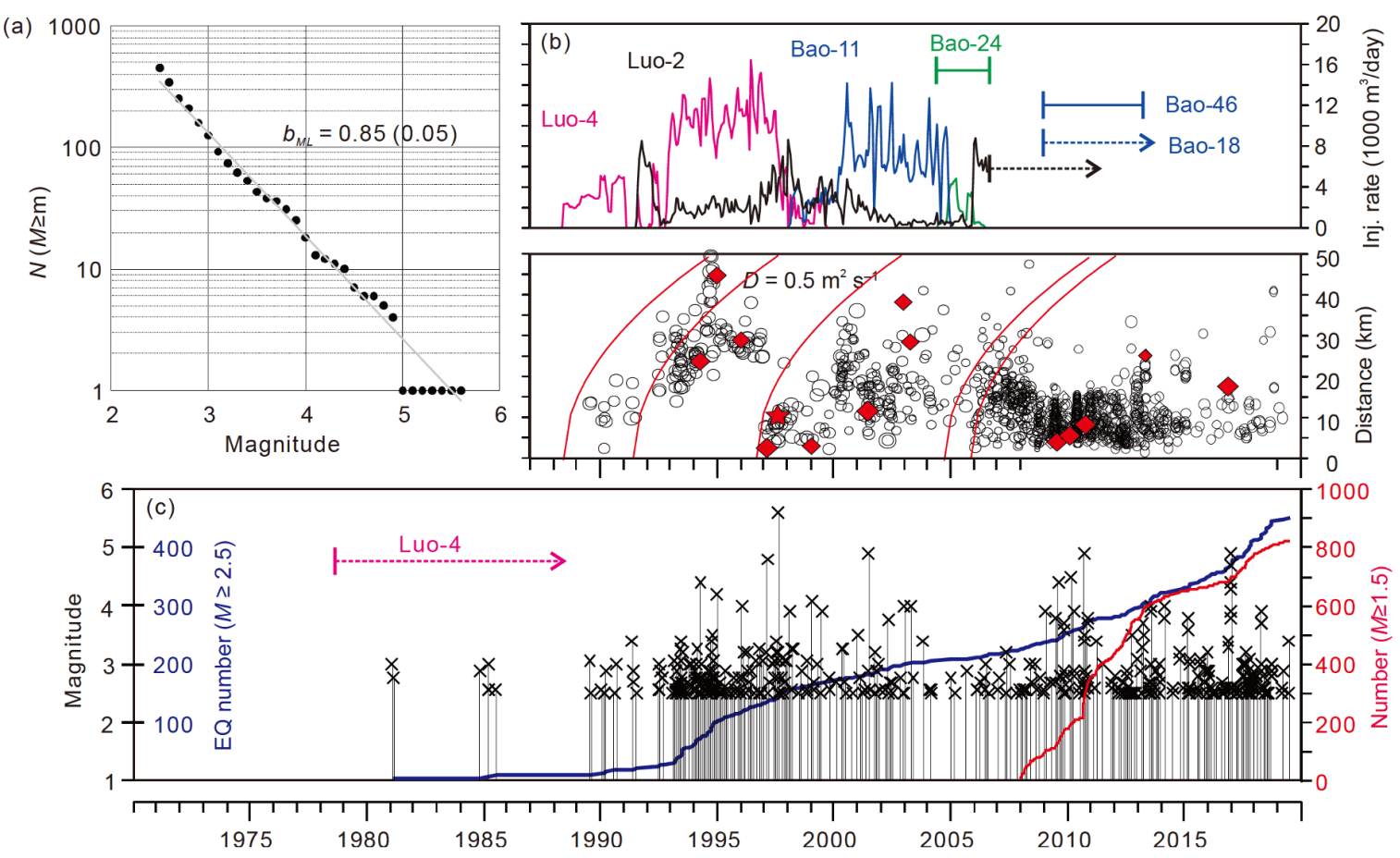

Figure 9 Comparison of injection rate, earthquake magnitude, cumulative number of events, and hypocenter migration pattern (distance to the Luo-4 well) in the Rongchang gas field and surrounding areas.

\section{Seismicity in Weiyuan-Rongxian shale gas demonstration block}

As discussed above, the shale gas industry breakout in China began in 2010, initiated by the development of the first Si- lurian shale gas well in the Weiyuan-Rongxian (also called the Weiyuan) shale gas demonstration block (h1 in Figure 2), located in the central uplift of the Sichuan Basin. Following the systematic HF operations in horizontal wells that began in 2015 , seismic activity increased dramatically and clus- 
tered around the wells.

Because no previously published works have described seismicity in the Weiyuan-Rongxian shale gas demonstration block, we present our preliminary results here. The seismicity observed thus far indicates that this area can be divided into two distinct subblocks for convenience: Weixi in the west and Weidong in the east, indicated as $\mathrm{A}$ and $\mathrm{B}$, respectively, in Figure 10.

To relocate seismic events and the inverse full moment tensor of the largest events, we constructed two velocity models based on the results of seismic ambient noise tomography (Wang et al., 2013). The preferred models, "ctSC_NT" and "esSC_NT," are based on mean S velocities $(V s)$ of the central and south Sichuan Basin, respectively (Figure S3). For the Weiyuan-Rongxian area, the ctSC_NT model was used for both hypocenter relocation and moment tensor inversion.

By use of phase data manually picked and compiled by the Sichuan Earthquake Administration and the double-difference location method (Waldhauser and Ellsworth, 2000), we relocated 5404 hypocenters (1904 in Weixi and 3500 in Weidong) from $6051 M \geq 1.5$ earthquakes (2071 in Weixi and 3980 in Weidong) for the period from 2015 through Feb. 2019. For the period from Mar. 2019 to Mar. 2020, 7192 of 7547 (3053 of 3300 in Weixi and 4139 of 4247 in Weidong) $M \geq 1.2$ events were relocated. The resulting hypocenter locations showed definite improvements but remained imprecise in hypocenter depth for the period before Mar. 2019. Assisted by the installation of additional seismic stations after the M4.9 event on 25 Feb. 2019, earthquakes observed since 1 Mar. 2019 were resolved with improved horizontal and vertical precisions (Figure 10).

We further inverted the focal mechanism solution and the moment tensor of $M_{\mathrm{W}}>3.5$ earthquakes using the gCAP method, in which the full waveforms of body and surface waves recorded by broadband seismometers were used (Zhu and Ben-Zion, 2013; Zhu and Helmberger, 1996). The full moment tensors were estimated by a grid search with respect to the moment magnitude (in increments of 0.01 ) and the strike, dip, and rake angles (increments of $5^{\circ}$ ) of the fault plane. The general seismic moment tensor was decomposed into double-couple, isotropic, and compensated linear vector dipole components (Zhu and Ben-Zion, 2013). In total, reliable solutions of $11 M_{\mathrm{W}}>3.5$ earthquakes until the end of 2019 were obtained. All of these events show a reversedominated mechanism with a negligible non-double-couple component (Figure 10, Table 2, Figures S4 and S5).

In the Weidong subblock, detailed data obtained by downhole monitoring and template-matching technology revealed, in addition to microseismicity within the treatment zones, out-zone seismicity (indicating seismicity outside the treatment zone) as well (Chen et al., 2018). The out-zone seismicity, also referred to as a distant cluster, was clearly linked with reactivation of pre-existing faults and demonstrated a lower $b$-value as compared with the in-zone seismicity. The largest earthquake observed so far was a M3.6 event until a M5.4 event occurred on 8 Sept. 2019. Then, on 18 Dec. of the same year, a $M 5.2$ event occurred about $4 \mathrm{~km}$ northeast of the M5.4 event, and another M5.2 event occurred on 18 Dec. 2019. During this time window, the nearby W204-H37 and H42 wells were undergoing HF (Figures 10 and 11). The focal mechanisms of the M5.4 and M5.2 earthquakes are similar, and their strike/dip/rake values are $25^{\circ} / 39^{\circ} / 70^{\circ}$ and $20^{\circ} / 41^{\circ} / 71^{\circ}$, respectively (Table 2, Figure S5). The depth of the relocated hypocenter is concentrated between 1 and $5 \mathrm{~km}$, and part of the earthquake is located in the crystalline basement (Figure 10b). The epicenter of the M5.4 earthquake is very close to the fracturing well platform W204-H37, and the centroid depth is also consistent with the horizontal well depth (Figure 10). By integrating relocated hypocenter data, especially the aftershock distribution 2 weeks after the M5.4 earthquake, and CMT results, we speculate that the seismogenic fault is a reverse fault, northnortheast striking and east-southeast dipping with a dip angle of about $40^{\circ}$, as shown in Figure 10.

In contrast to the Weidong subblock, the Weixi subblock demonstrates more destructive earthquakes. Since 2015, nine earthquakes of $M 4$ to $M 4.9$ were observed. Particularly, three earthquakes having magnitudes of $4.7,4.3$, and 4.9 occurred on 24 and $25 \mathrm{Feb}$. 2019, causing two fatalities. At this point, the nearby W202-H55 well was ending HF, and H62 was undergoing HF (Figures 10 and 11). After these earthquakes, all injections in Rongxian County were interrupted for several weeks, and some well pads of drilled wells might be permanently given up, leading to huge economic loss. Close to the hypocenters of events on 24 and 25 Feb. 2019, M4.3 and M4.4 events occurred on 8 Sept. 2019 and 17 Feb. 2020, respectively. Hypocenter depths were concentrated between 1 and $5 \mathrm{~km}$ (Figure 10b). The aforementioned three $M>4$ events were located very close to the active W204-H62 well pad, and the CMT depths were the same as or less than the depths of the horizontal wells (Figure 10b). On the map view, these earthquakes are close to the mapped Molinchang fault (F1 in Figure 10). Thus far, until the end of 2019, the existing horizontal wells, in which $\mathrm{HF}$ was performed, were more than $2 \mathrm{~km}$ away from the fault at the fracturing depth. By combining various data, including surface deformation from InSAR data (ongoing study), we conclude that the seismogenic faults are hidden reverse faults that are trending near north-south and dipping east of their conjugate faults (Figure 10). However, the Molinchang fault is also worthy of attention. Many planned horizontal wells are very close to the fault plane at the fracturing depth. In fact, a M4.3 earthquake on 16 Feb. 2020 was located on the Molinchang fault.

To test whether the seismic activity has a certain periodi- 

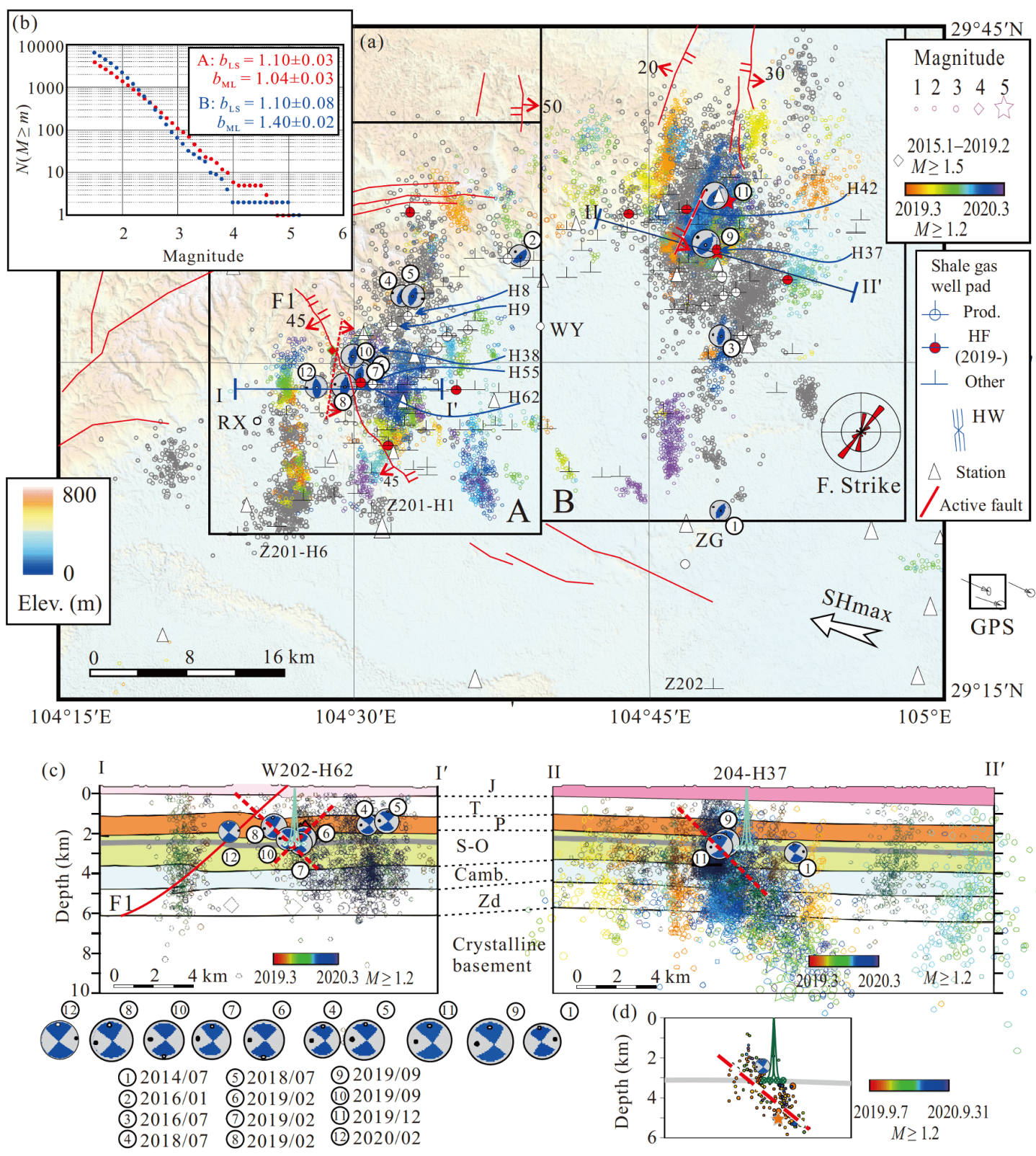

Figure 10 (a) Map of epicentral distribution in the Weiyuan-Rongxian area during two periods: (1) from 2014 through 2018 and (2) from 1 Jan. 2019 to 23 June 2019, overlaid with well pads. Focal mechanisms of $M_{\mathrm{W}}>3.5$ earthquakes are shown with the lower-hemisphere projection of focal spheres. (b) Frequency-magnitude correlation and seismic $b$-values for Weixi (A) and Weidong (B) subblocks. (c) Earthquake hypocenters and CMTs projected on simplified geological sections (Zou et al., 2015). (d) Hypocenter distribution within 2 weeks after the M5.4 earthquake on 7 Sept. 2019. F1 in (a) and (c) marks the mapped Molinchang fault. Dashed red lines indicate suggested source faults of the major earthquakes. HW indicates the typical pattern of horizontal wells in the Weiyuan shale gas block. The large arrow shows the orientations of the maximum horizontal principal stress (SHmax) obtained by this study. The F. strike indicates the strike distribution of preexisting natural fractures obtained from borehole data (Chen et al., 2018).

city, we calculated Schuster's spectrum of seismic activity, which is useful for detecting unknown periodicity and nonuniformity of the seismicity (Ader and Avouac, 2013). Schuster's spectrum clearly showed a diurnal period (Figure S6a). Because no semidiurnal period was detected and the cycle of a diurnal period is exactly 1 day, the observed periodicity cannot be attributed to the result of tidal effects. In addition, the hourly frequency of earthquakes showed that the frequency during daytime ( 9 a.m. -8 p.m.) is significantly greater than that during nighttime (Figure S6b). Thus, similar to the seismicity in the Changning shale gas block (Lei et al., 2019b), the diurnal periodicity and daily non-uniformity of seismicity reflects some human factors, such as the regular daily injection activities. Interestingly, the seismic activity during the COVID-19 pandemic, from 20 Jan. to 8 Mar. 2020, declined significantly, reflecting the suspension of HF due to the Chinese Spring Festival holiday and the following pandemic shutdowns. 
Table 2 Fluid overpressure $\left(\Delta P_{\mathrm{f}}\right)$ at the source point of $M_{\mathrm{W}}>3.5$ earthquakes derived from stress pattern and focal mechanism solutions

\begin{tabular}{|c|c|c|c|c|c|c|c|c|c|c|c|}
\hline \multirow{2}{*}{ No. } & \multirow{2}{*}{ Date } & \multirow{2}{*}{$\mathrm{H}$} & \multirow{2}{*}{$M_{\mathrm{W}}$} & \multirow{2}{*}{$H(\mathrm{~km})$} & \multirow{2}{*}{$\Delta P_{\mathrm{f}}$} & \multicolumn{3}{|c|}{ Fault-1 } & \multicolumn{3}{|c|}{ Fault-2 } \\
\hline & & & & & & Strike & Dip & Rake & Strike & Dip & Rake \\
\hline 1 & $2014-07-11$ & 19 & 3.58 & 2 & 7.1 & $25^{\circ}$ & $41^{\circ}$ & $87^{\circ}$ & $209^{\circ}$ & $49^{\circ}$ & $93^{\circ}$ \\
\hline 2 & 2016-01-07 & 12 & 3.74 & 3.5 & 1.3 & $45^{\circ}$ & $20^{\circ}$ & $91^{\circ}$ & $224^{\circ}$ & $70^{\circ}$ & $90^{\circ}$ \\
\hline 3 & $2016-07-27$ & 07 & 3.71 & 2.9 & 6.9 & $4^{\circ}$ & $33^{\circ}$ & $85^{\circ}$ & $190^{\circ}$ & $57^{\circ}$ & $93^{\circ}$ \\
\hline 4 & $2018-07-23$ & 07 & 3.73 & 1.6 & 3.9 & $15^{\circ}$ & $44^{\circ}$ & $86^{\circ}$ & $201^{\circ}$ & $46^{\circ}$ & $94^{\circ}$ \\
\hline 5 & $2018-07-23$ & 07 & 4.15 & 1.4 & 2.1 & $13^{\circ}$ & $47^{\circ}$ & $85^{\circ}$ & $200^{\circ}$ & $43^{\circ}$ & $95^{\circ}$ \\
\hline 6 & $2019-02-24$ & 05 & 4.27 & 2.31 & 5.4 & $10^{\circ}$ & $46^{\circ}$ & $90^{\circ}$ & $190^{\circ}$ & $44^{\circ}$ & $90^{\circ}$ \\
\hline 7 & $2019-02-25$ & 08 & 4.06 & 2.53 & 3.3 & $5^{\circ}$ & $50^{\circ}$ & $76^{\circ}$ & $206^{\circ}$ & $42^{\circ}$ & $106^{\circ}$ \\
\hline 8 & $2019-02-25$ & 13 & 4.53 & 1.74 & 4.5 & $0^{\circ}$ & $36^{\circ}$ & $77^{\circ}$ & $195^{\circ}$ & $55^{\circ}$ & $99^{\circ}$ \\
\hline 9 & 2019-09-08 & 06 & 4.92 & 2.48 & 7.3 & $25^{\circ}$ & $39^{\circ}$ & $70^{\circ}$ & $230^{\circ}$ & $54^{\circ}$ & $105^{\circ}$ \\
\hline 10 & 2019-09-08 & 10 & 4.15 & 2.30 & 4.6 & $11^{\circ}$ & $46^{\circ}$ & $90^{\circ}$ & $191^{\circ}$ & $44^{\circ}$ & $90^{\circ}$ \\
\hline 11 & $2019-12-18$ & 08 & 4.73 & 2.54 & 10.6 & $20^{\circ}$ & $41^{\circ}$ & $71^{\circ}$ & $225^{\circ}$ & $52^{\circ}$ & $106^{\circ}$ \\
\hline
\end{tabular}
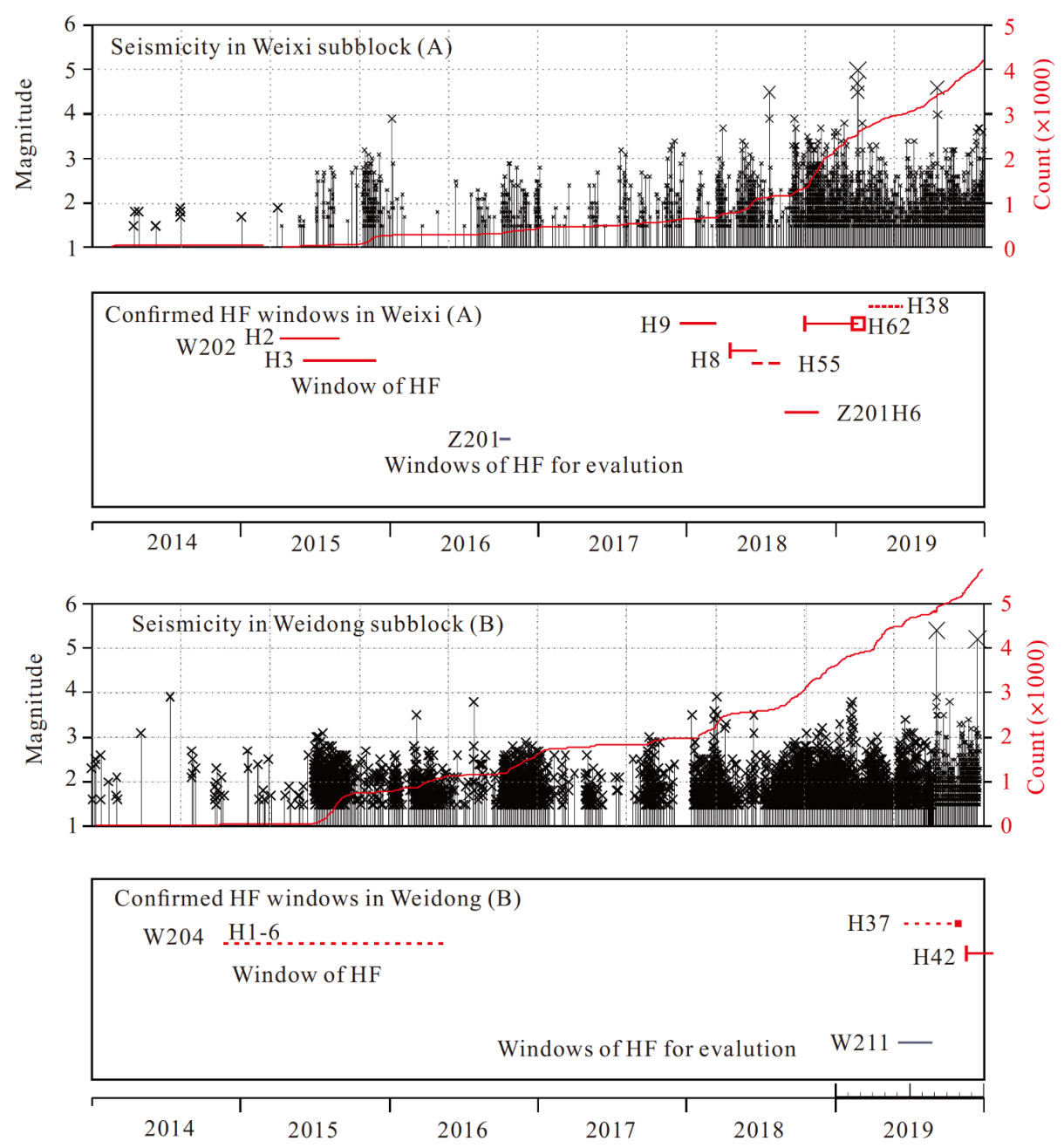

Figure 11 Magnitude and accumulated number of $M \geq 1.5$ earthquakes against time, overlapped with time window of hydraulic fracture operations, which were confirmed by field surveys and thus incomplete, in the western Weiyuan (Weixi, A) and eastern Weiyuan (Weidong, B) subblocks.

The same method used for the Shangluo shale gas site (Lei et al., 2019a) and the 11 reliable focal mechanism solutions aforementioned were used to estimate the regional stress pattern (Figure 12). The maximum and intermediate princi- pal stress axes are almost horizontal. The minimum principal stress axis is nearly vertical. The maximum principal stress axis has a plunge of $6.2^{\circ} \pm 3.0^{\circ}$ and an azimuth of $106^{\circ}$, showing a certain difference with the result of $90^{\circ}$ estimated 
from the borehole data (Chen et al., 2018). The obtained stress shape ratio was $\phi=0.87 \pm 0.09$, close to the results for the Rongchang wastewater disposal site. With an assumed critical stress state, a CFS increment of 0.7-6.4 MPa, or an overpressure of 1.3-10.6 MPa, was sufficient to cause these $M_{\mathrm{W}}>3.5$ earthquakes (Table 2).

Different responses in the Weidong and Weixi subblocks can be interpreted by the differences in size and density of pre-existing faults. The sediment deformation in the Weidong subblock is relatively weak and fewer faults exist in the sedimentary layers, while the Weixi subblock, located in the south wing of the famous Weiyuan anticline, contains a number of faults longer than $10 \mathrm{~km}$ (Figure 10).

\section{Lessons and opportunities from the Sichuan Basin}

The Sichuan Basin has a wide range of geological and tectonic environments, with variations in structure maturity, fault orientation, and stress criticality, which makes the seismic activity of this area very helpful for understanding problems in earthquake seismology. In addition, different types of fluid injection, with differences in pressure, depth, rate, and volume, provide us with opportunities and scientific challenges in research on the induced seismic activity here. Typical cases of injection-induced seismicity observed thus far in the southwestern Sichuan Basin provide very good opportunities for comprehensive studies. Full cooperation from the oil company, including detailed injection data and information on upcoming injection plans, is necessary for deepening our understanding of injection-induced seismicity and ultimately finding ways to balance and accept these risks. The ongoing establishment and perfection of governmental regulation is probably an urgent necessity for China, a rapidly developing country.

\subsection{Injection-induced seismicity in south Sichuan Basin}

As described in Section 3, since 1600, 32 earthquakes of $M \geq 5$ have occurred within the Sichuan Basin area (Figures 1 and 2), excluding aftershocks of the M6 Changning earthquake on 17 June 2019. Among these 32 events, at most 20 events are considered to be natural in origin. These natural earthquakes were distributed over various sites within the Sichuan Basin, but more events were located in the south. Although the present-day strain rate is very low, the stress level of the crust is high, and favorably orientated faults are critically stressed. Several earthquakes are isolated in time and space, without clear foreshocks and aftershocks. Some earthquake sequences are clustered in space, with some foreshocks and a large number of aftershocks, which last from months to up to 2 years. Some sequences show tran- sitional characteristics between the two types, and there are certain aftershocks, but the maximum aftershock magnitude is much smaller than that expected from Båth's law (Båth, 1965), which states that the difference in magnitude between a main shock and its largest aftershock is typically 1.1-1.2, regardless of the mainshock magnitude.

Since 1950, except for some isolated events at Suining, Tongjing, Wulong, and Qingbaijiang, at least $12 M \geq 5$ events were somewhat associated with fluid injection in deep wells for (1) disposal of wastewater in depleted gas reservoirs, (2) dissolving deep rock salt, and (3) HF in shale formations. Thus, the estimated long-term background event rate of natural earthquakes is $\sim 0.05$ events $\mathrm{yr}^{-1}$. The estimated mean event rate after 1950 is $\sim 0.17$ events $\mathrm{yr}^{-1}$, mainly due to induced events. Fluid injection has increased the occurrence rate of $M \geq 5$ earthquakes at least threefold (Figure S7a). If we focus on $M \geq 4$ earthquakes after 1970, the annual frequency of events is 0.57 events in the $1970 \mathrm{~s}$, and then the rate had a stepwise increase, reaching 5.2 events $\mathrm{yr}^{-1}$ for the period from 2015 to June 2019, just before the Changning swarm. The continuous increase of moderate and strong earthquakes in the past 30 years is obvious (Figure S7b).

For some cases, such as the Rongchang and Shangluo fields, previous studies have found convincing chains of evidence supporting the connection between seismicity and injection. At the Changning shale gas site, the largest $M_{\mathrm{L}} 5.7$ and $M_{\mathrm{L}} 5.3$ earthquakes were located very close to the HF zones of horizontal wells, in which HF was ongoing when the earthquakes occurred. Thus far, injection-induced earthquakes with a magnitude greater than 5.5 have been documented at sites of wastewater disposal (Skoumal et al., 2018) and an EGS (Kim et al., 2018). The $M_{\mathrm{L}} 5.7$ Xingwen earthquake is, to date, the largest HF-induced earthquake. From the limited studies of these earthquakes, it is possible to draw some general insights.

In the Shuanghe salt mine area, seismicity is clearly correlated with the injection history and water loss in the salt mine. We agree with the conclusion of previous studies (Ruan et al., 2008; Sun et al., 2017) that earthquakes occurring before the $M 6$ sequence were induced (or triggered) by long-term deep well injections.

It is worth noting that the original earthquake catalog contains many blasting events at quarries of cement plants and for other purposes. Figure S8 shows a typical case of numerous blasting events around cement plants in Xunchang Town, west of the Changning anticline. The hourly event rate distribution shows two prominent peaks at 12 noon and $6 \mathrm{p}$. $\mathrm{m}$., with the vast majority of events occurring during the daytime. Interestingly, some events have been observed during the night. In addition, the frequency-magnitude distribution follows the Gutenberg-Richter relation and shows a $b$-value close to 1 , which is the global mean value for earthquakes. Thus, events induced by blasting might be 

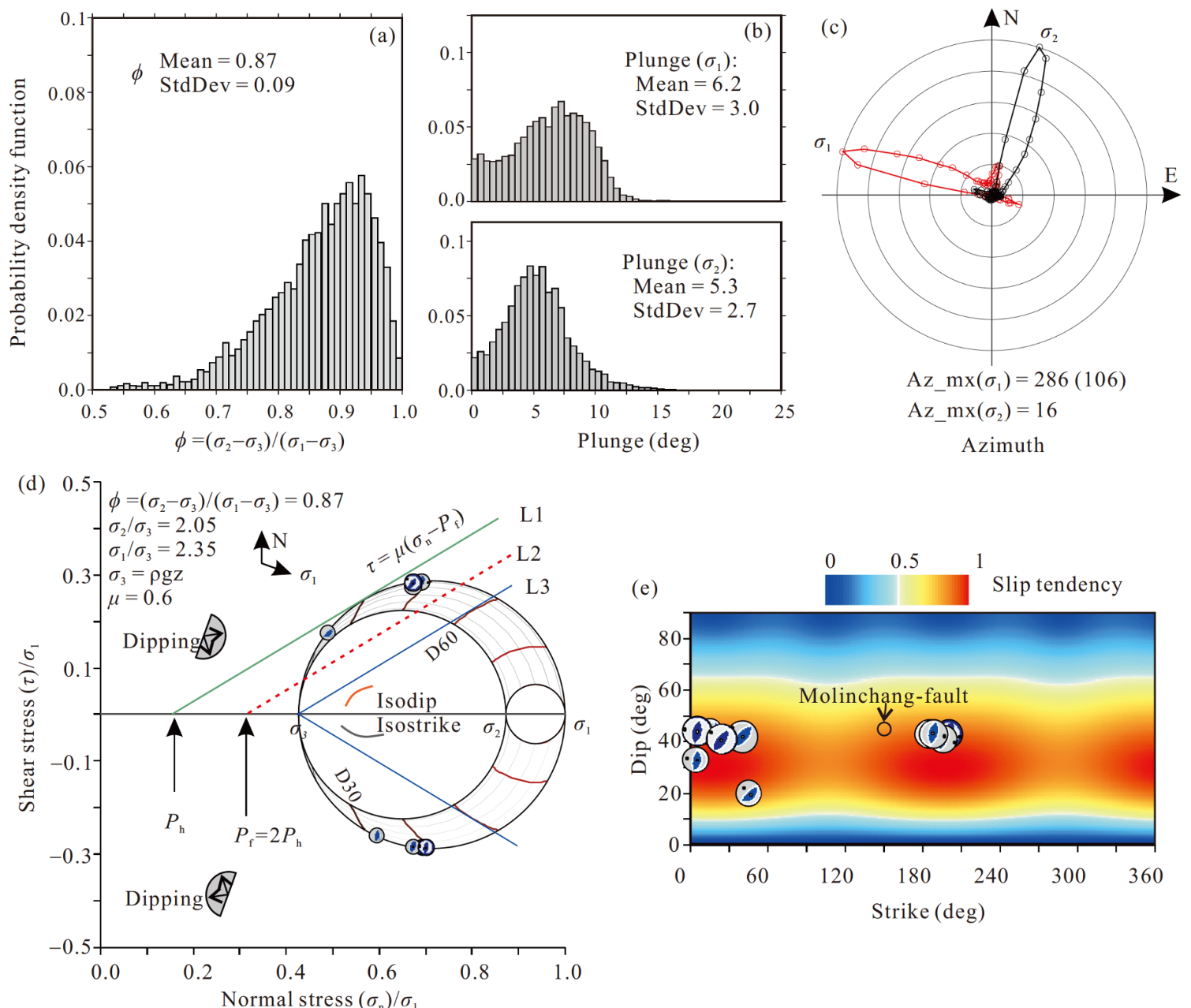

Figure 12 (a) Estimated stress shape ratio $(\phi)$ of the principal stresses and estimated maximum principal stress axis in terms of (b) plunge angle and (c) azimuth for the Weiyuan-Rongxian shale gas demonstration block. (d) Mohr's circle in normalized normal stress and shear stress coordinates. (e) Normalized slip tendency as a function of fault strike and dip.

important and worthy of further study. More specifically, blasting events should be carefully excluded from future studies.

\subsection{Role of overpressured fluid in natural and induced earthquakes}

By ignoring the poroelastic effect due to water injection, the estimated fluid pressure required to activate the source faults of $M \geq 4$ events in the Sichuan Basin ranges from less than $1 \mathrm{MPa}$ to a few tens of $\mathrm{MPa}$, indicating that some faults are favorable but more faults are unfavorable for rupture under the present-day stress regime. For most $M \geq 4$ events, the amplitude of increased CFS from injection operations is sufficient for reactivating the source fault (Lei et al., 2019a). However, for some earthquakes, such as those with deeper focal depth or less favorable fault orientation and dip angle at the Shuanghe salt mine site, other factors are needed for giving a reasonable interpretation. Stress inhomogeneity and overpressured fluid in deeper reservoirs are possible factors. In the Sichuan Basin, overpressured natural gas reservoirs with a pressure ratio greater than 2 are not rare. For example, as reviewed in Section 3.3.1, the 2010 M5.1 Suining earthquake, an isolated event, is suggested to have been induced by episodic fluid flow from overpressured aquifers in the Jialingjiang formation ( $\mathrm{T} 1 \mathrm{j})$ through fault-valve behavior. Similarly, the Tongjing M5.2 and M5.4 sequence in 1989 and Wulong M5.0 event in 2017 could also have been driven by overpressured fluid flowing from deep reservoirs. If episodic fluid flow is the dominant driver, the resulting seismicity may show various patterns (isolated or swarms) depending on the volume and mobility of the fluid, complexity of the fault system, and stress criticality.

As shown in Section 3, there are many isolated earthquakes and sequences of abnormally few aftershocks in the Sichuan Basin, including natural and induced events. For these seismic activities, as a reasonable guess, we believe that the fault stress as a whole is subcritical and the pressure 
of the deep fluid is high enough to promote fault slip, but the fluid source is limited and recharge is weak. Therefore, it can only trigger a main event with abnormally low aftershock activity. This is a very interesting question for induced earthquakes and occasional moderate to strong earthquakes in stable areas, and it is worthy of further study.

\subsection{Impact of 2008 Wenchuan earthquake on the Si- chuan Basin}

On 12 May 2008, a $M_{\mathrm{W}} 7.9$ Wenchuan earthquake occurred along the Longmenshan fault zone in the northern margin of the Sichuan Basin (Wang et al., 2008). Therefore, whether the recent seismicity in the Sichuan Basin has been affected by the Wenchuan earthquake is worth exploring. To this end, we calculated the influence of the Wenchuan earthquake fault displacement on the Sichuan Basin. In the calculation, the slip model based on far-field body waveforms and nearfield coseismic displacement data (Wang et al., 2008) was used. It was found that, for the dominant northeast-striking thrust fault in the Sichuan Basin, most areas of the Sichuan Basin have a negative CFS value (Figure 2). The southwestern margin of the basin, including the Weiyuan-Rongxian and Changning shale gas block, shows positive CFS, but its value is less than $0.001 \mathrm{MPa}$. Therefore, the Wenchuan earthquake had little role in the increasing earthquake activity in fields with injection activities. At the same time, the Wenchuan earthquake produced an extensional strain in the central and southeastern parts of the Sichuan Basin. Several isolated earthquakes that may be related to deep natural fluids all fell within this area (Figure S9). Extensional strain has a role in promoting fluid-driven fault reactivation. This is a very interesting topic worthy of further study.

\subsection{Features of injection-induced seismicity}

Some features of injection-induced seismicity are common to all types of fluid injections in the Sichuan Basin:

(1) Major events demonstrate a shear rupture mechanism with only a few percent of non-double-couple components under the level of uncertainty.

(2) For many cases, the pressure increase due to injection is sufficient to cause the induced seismicity associated with the rupture of pre-existing fractures and reactivation of known or unknown faults and other weak planes, including joints and bedding surfaces. Stress change due to poroelasticity may play a role of lesser importance.

(3) A uniform regional stress field is insufficient to explain all focal mechanisms observed, which demonstrates that the local stress field at the reservoir scale is more or less inhomogeneous.

(4) Seismic productivity depends on the injection well location, that is, the tectonic and geomechanical condition of the formations into which fluid is injected.

(5) The upper bound of magnitude is determined by geological conditions rather than injection pressure and cumulative volume of injected fluid. However, increasing injection volume or an increasing number of injection sites for shale gas production likely increases the probability of the fluids encountering larger faults. Thus, from a broad perspective, one can expect an apparent correlation between total injection volume and the maximum magnitude. Such a correlation is important for a global risk assessment in a statistical manner.

(6) Generally speaking, injection-induced seismicity shows that the Omori-type aftershock productivity is very low and characterized by small $\alpha$ value $(<1.0)$ and large fraction (50-90\%) of forced seismicity in the epidemic-type aftershock sequence model (Lei et al., 2017a, 2013, 2019a, 2008). These features are also evidence of injection-induced seismicity. At some long-term injection sites, such as the Rongchang disposal site, increasing forced seismicity was observed.

(7) No clear differences have been found between natural origin events and induced earthquakes of $M \geq 4$ with regard to earthquake seismological aspects. A reliable way to identify induced seismicity depends on a chain of multiple lines of evidence, including spatiotemporal correlation between seismicity and injection, parameters involved in statistical models, and fault reactivation analysis.

(8) In some cases, the largest events may have occurred during the very beginning stages of injection (Lei et al., 2013), as well as at later stages (Lei et al., 2008). The time lag depends first on the distance between the injection location and the source fault. In some cases, seismicity shows progressively increasing maximum magnitude (such as at the Rongchang site for wastewater disposal). In other cases, the maximum magnitude jumps from less than 2 to greater than 4.

(9) Post-injection seismicity after shutdown of an injection well normally decayed quickly in cases of short-term injection, such as HF in a single pad and short-term disposal for a few years. Conversely, in cases of long-term injection (tens of years), such as wastewater disposal at Rongchang and Kongtan and salt mining at Ziliujing and Luocheng-Changshan, post-injection seismicity may stay at a relatively higher level for quite a long time.

(10) Large earthquakes were normally initiated within the zone and propagated by rupturing beyond the zone.

(11) As long as the injection continued, the induced seismicity did not stop. Meanwhile, the natural earthquake interval did not exceed 2 years, and some events were isolated.

At the same time, each type of injection-induced seismicity also shows some individual features. In cases of wastewater disposal, when fluid is disposed of in a depleted formation at an injection rate lower than a certain threshold, fluid could 
enter the well under gravity flow. No clear seismicity was observed under these conditions. Clear seismicity was generally initiated within days after the beginning of pumped injection under pressure.

In the case of HF for shale gas, the injection pressure is very high, higher than the minimum principal stress (the vertical overburden gravity in the Sichuan Basin), but very short (a few hours) for each fracture stage. When HF moves to the next stage, the fractured stages at the front of the horizontal well are closed by a bridge plug. Then, the pressure in the fractured volume can diffuse along pre-existing permeable channels. After all stages of HF are completed, it takes a few months for the flowback process to release major pressure and then change to gas pressure, which is controlled by the production rate. As a result, the injection-induced seismicity at shale gas sites shows some specific features, and further studies are required.

\subsection{Conditions of high-level injection-induced seismi- city in Sichuan Basin}

First, it is important to note that, similar to other sites in the world (Ghofrani and Atkinson, 2016), the likelihood of HFinduced seismicity varies widely across both local and regional scales. Many injection sites in the Sichuan Basin did not show significant seismic activity. Local geology is thus a key factor.

Pre-existing faults within brittle formations are necessary conditions for inducing significant earthquakes, especially for felt earthquakes. Small and immature faults exist widely in the brittle formations in the southern fold zones of the Sichuan Basin, resulting in a high level of injection-induced seismicity.

According to Section 2.2, the slip tendency of pre-existing faults is a function of stress pattern and fault orientation within the principal stress axis, and thus the patterns of tectonic stress fields and fault orientations are also key factors. After experiencing multiple tectonic movements, the Sichuan Basin shows multiple groups of faults. Fewer faults are favorable (i.e., having greater slip tendency) and more faults are unfavorable (smaller slip tendency) for rupture under the present-day stress field. This is a possible reason that induced seismicity at some sites (such as Fuling) was very low, while at other sites (such as Shangluo and west Weiyuan) it was very high.

In the Sichuan Basin, thus far, systematic and large-scale $\mathrm{HF}$ activities have been carried out in three demonstration blocks: (1) Jiaoshiba in the Fuling block, (2) the WeiyuanRongxian block, and (3) the Changning block. Among these blocks, the Changning block shows the highest level of induced seismicity. As discussed in Section 3.5, to date, 10 $M \geq 4.0$ earthquakes, including $4 M \geq 5.0$ events, have been observed. The Weiyuan-Rongxian shale gas block can be divided to two distinct subblocks: Weidong in the east and Weixi in the west. The western Weixi subblock also shows a high level of induced seismicity. Since 2016, six earthquakes having a $M_{\mathrm{L}}$ of 4-4.9 have been observed. The $M_{\mathrm{L}} 4.9$ event on 25 Feb. 2019 killed two persons. The east Weiyuan subblock also shows a high level of injection-induced seismicity. However, despite the fact that HF treatment in the same Longmaxi shale formation was performed with a fluid pressure higher than that used at the Weixi and Changning sites, the largest earthquake observed was a $M_{\mathrm{L}} \sim 3.6$ event until a M5.4 earthquake occurred on 16 Sept. 2019. The Jiaoshiba site shows the lowest level of induced seismicity.

The fault stability analysis in Section 2.2 shows that under iso-compression, shear stress on any fault surface is 0 , which cannot produce rupturing. Differential stress is a necessary condition for fault reactivation. The sporadic distribution of natural earthquakes within the Sichuan Basin indicates that differential stress is sufficient to activate the source faults. In agreement with GPS-derived displacement, stress inversion shows that the Sichuan Basin generally has a compression stress field, and the maximum principal stress axis is almost horizontal with a direction southeast-east to east-west. In some local areas in the southeastern fold belt, such as the Changning anticline, the direction may rotate more or less. The minimum principal stress axis is nearly vertical and thus can be estimated from the overburden. The intermediate principal stress axis is also nearly horizontal, but its amplitude varies widely, showing a stress shape ratio from 0.1 to more than 0.9. As seen in Figure 3, slip tendency is a function of fault strike, dip angle, and stress shape ratio. Faults with a strike and dip fall in the region of higher slip tendency and are reactivated more easily. In Weiyuan and Rongchang, the azimuths of the maximum horizontal stress directions are $106^{\circ}$ and $120^{\circ}$, respectively, while the stress shape ratios are $\phi=0.87$ and 0.94 . In these regions, reverse faults of a dip of $25^{\circ}-30^{\circ}$ are favorable for rupturing. In the Shangluo shale gas block within the Luochang-Jianwu syncline, the azimuth of the maximum horizontal stress direction is $117^{\circ}$, and the stress shape ratio is 0.15 . Both strike-slip and reverse faults can be reactivated if their slip-tendency is high enough.

Different responses in the Weiyuan and Changning blocks can be interpreted by the differences in scale and density of pre-existing faults. Because the east Weiyuan block is located in the central uplift of the Sichuan Basin, as compared with the Changning block in the southern fold zone, sediment deformation here is relatively weak, with fewer faults in the sedimentary layers (Lei et al., 2017a), and thus the probability of encountering large faults is relatively low. As aforementioned, the Weixi subblock corresponds to the southeast wing of the Weiyuan anticline, which has a number of mapped faults, and thus the probability of encountering large faults is greater than that in the eastern Weiyuan subblock. The Jiaoshiba site is located in the southeastern fold 
zone, and thus it shows a higher density of faults, similar to the Changning and Weixi sites. Fortunately, major faults here are almost vertical and badly oriented for rupture under the current stress field. In the Jiaoshiba site, differences between the maximum and minimum horizontal in-situ stress is small (3-7 MPa), significantly smaller than that in the Changning block ( 22 MPa) (Wang et al., 2016). In addition, injection pressure for HF in the Jiaoshiba site averaged $10 \mathrm{MPa}$ lower than that in the Changning block. Thus, the lower seismicity in the Jiaoshiba site could be explained by the stress pattern, under which stress from HF was insufficient to activate unfavorable faults.

\subsection{Are injection-induced earthquakes as large as ex- pected?}

Given the fact that significant earthquakes occurred because of reactivation of relatively large faults, the maximum magnitude of potential earthquakes is ultimately determined by the size of a pre-existing fault and the criticality of the stress acting on it. Thus, injection factors may control when the maximum earthquakes occur. Injection pressure and injected volume are also important factors because higher injection pressure and larger injected volume result in the pore pressure rising over a wider area, and thus increasing the probability of reactivating larger faults.

On the whole, the maximum earthquake magnitudes observed in the study areas are as large as statistically expected from the Gutenberg-Richter relationship between frequency and magnitude (Lei et al., 2019b), in agreement with that observed at other sites (van der Elst et al., 2016). However, at a local level, some of the largest events observed so far are outliers in the power law of seismicity. Such events were also observed at other sites, such as Alberta, Canada (Eyre et al., 2019). The mechanisms and conditions for such extreme events, most of them destructive, are important and emergent issues for further study.

The shear mechanism and pattern of hypocenter distribution demonstrate that most earthquakes resulted from the reactivation of pre-existing faults in the sediments, some of them previously unknown. Injected fluids diffusing outward along the pre-existing faults, which were already stressed, play a role in weakening and reactivating these faults. Thus, in the study region, increasing the CFS (or slip tendency) of pre-existing faults is the primary mechanism that induces earthquakes (Figure 3). This mechanism may give rise to damaging earthquakes if a reactivated shallow fault has dimensions on the order of a few kilometers. Water can have a very large effect on rock strength, especially at elevated temperatures. In agreement with other studies (Ellsworth et al., 2019; Norbeck and Rubinstein, 2018), under certain conditions, earthquake ruptures are able to propagate as sustained ruptures beyond the zone that experienced the pressure perturbation. The Xingwen M5.7 earthquake shows that a rupture nucleated within a zone of elevated pore pressure can unidirectionally propagate for several to about $10 \mathrm{~km}$ northward. The Shuanghe M6.0 earthquake nucleated at a position in the Shuanghe salt mine and unidirectionally propagated for more than $10 \mathrm{~km}$ westward. Note that the injected fluids need not migrate from the injection well to a fault for fault reactivation. The fault can be reactivated by an increase in fluid pressure, which can be transmitted across distances greater than the fluids actually move due to their low compressibility.

\section{Insights and challenges}

\subsection{Detecting early signs of fault reactivation}

As discussed in Section 5.4, some cases show progressively increasing maximum magnitude (such as the Rongchang site for wastewater disposal). In other cases, the maximum magnitude jumps from less than 2 to greater than 4 . Thus, a simple traffic signaling system does not work. Rather, advanced operation management systems are required for different sites. Wastewater is injected into depleted gas reservoirs of Permian limestone formations, which are associated with anticlines bounded by faults. Because the depleted gas reservoirs demonstrate very good permeability, they may respond quickly to faulting. In the Changning HF sites, because detailed injection data are not available, detailed correlations between HF activities and large earthquakes cannot be made. However, as indicated by a previous study (Lei et al., 2019a), large events followed a growing number of apparent foreshocks, raising the possibility of being alerted by some signs of fault reactivation from previous seismicity. Seismic $b$-values and other detailed information on out-of-zone seismicity is a potential indictor. A practically useful hazard model can be made through numerical approaches that involve detailed structures and consider the coupled interactions of fluid flow in faulted porous media and quasidynamic elasticity to investigate the earthquake nucleation, rupture, and arrest processes for cases of induced seismicity.

At sites without large-scale pre-existing faults, because induced seismicity was limited in zone (stimulated volume) and was mainly controlled by injection parameters, induced seismicity could be better controlled because seismicity faded out quickly after shut in. For such cases, as demonstrated by an EGS project, near-real-time seismic monitoring of fluid injection has allowed control of induced earthquakes via a well-designed traffic signaling system (Kwiatek et al., 2019). However, for worse cases that have caused devastating events, major seismicity resulted from reactivation of large-scale pre-existing faults having different maturity (Kozłowska et al., 2018; Lei et al., 2019b). On the one hand, 
mature faults in basements and immature faults in sediments demonstrated seismically different responses to injection operations (Kozłowska et al., 2018). On the other hand, earthquakes on immature faults produce stronger ground motions at all frequencies, as compared with those generated by earthquakes on mature faults (Radiguet et al., 2009). Thus, the structural maturity of faults is an important parameter that should be considered, and the shear behaviors of faults having different maturities should be fully investigated at all scales. The possibility of detecting early signs of fault reactivation, which might be a function of structure maturity, is a key issue in risk assessment and hazard mitigation of injection-induced seismicity.

Combining downhole observations with dense surface array observations produces more accurate microseismic imaging that can help identify unknown faults (Chen et al., 2018; Deng et al., 2007). Especially for immature sediment faults, due to negligible slip history, the fault surface must be rough, and thus small-scale ruptures are expected before a rupture is large enough to lead to destructive events. Microseismic diffusion along faults is an early sign of fault reactivation. For detecting early signs of fault reactivation, it is expected that we will be able to precisely determine the hypocenters of earthquakes with a cutoff magnitude as low as possible. Template-matching technology, which uses cross correlation of seismograms from multiple stations to detect and locate small earthquakes, is a promising approach.

\subsection{General framework for assessment and manage- ment of earthquake-related risks}

Figure 13 shows a flowchart for a general framework for assessment and management of risks related to induced earthquakes. Similar frameworks have been proposed for estimating fault stability during and after fluid injection for different fields (e.g., Rutqvist et al., 2015; Streit and Hillis, 2004). The coupled heat transfer, fluid flow, and rock mechanics (THM) simulation plays a key role. At first, a numerical model of a reservoir system centered on the injection site is created using existing geological and geophysical data, such as the mechanical and petrological properties of the major rocks in the reservoir system. Rock properties and the frictional properties of faults in each field, which govern fault instability (Kolawole et al., 2019), should be experimentally investigated using rocks collected from the field under well-controlled laboratory conditions. The role of external force heterogeneously and locally acting on a limited region of a fault plane, which is the cause of injectioninduced fault reactivation, should be fully investigated at the laboratory scale and upscaled to the reservoir scale through numerical approaches. It is especially important to describe faults in as much detail as possible. Then, numerical simulation should be performed with the assumed injection conditions. Because there are uncertainties in many aspects of the numerical model, such as small-scale inhomogeneity and upscaling, uncertainty analysis is necessary for a probability-

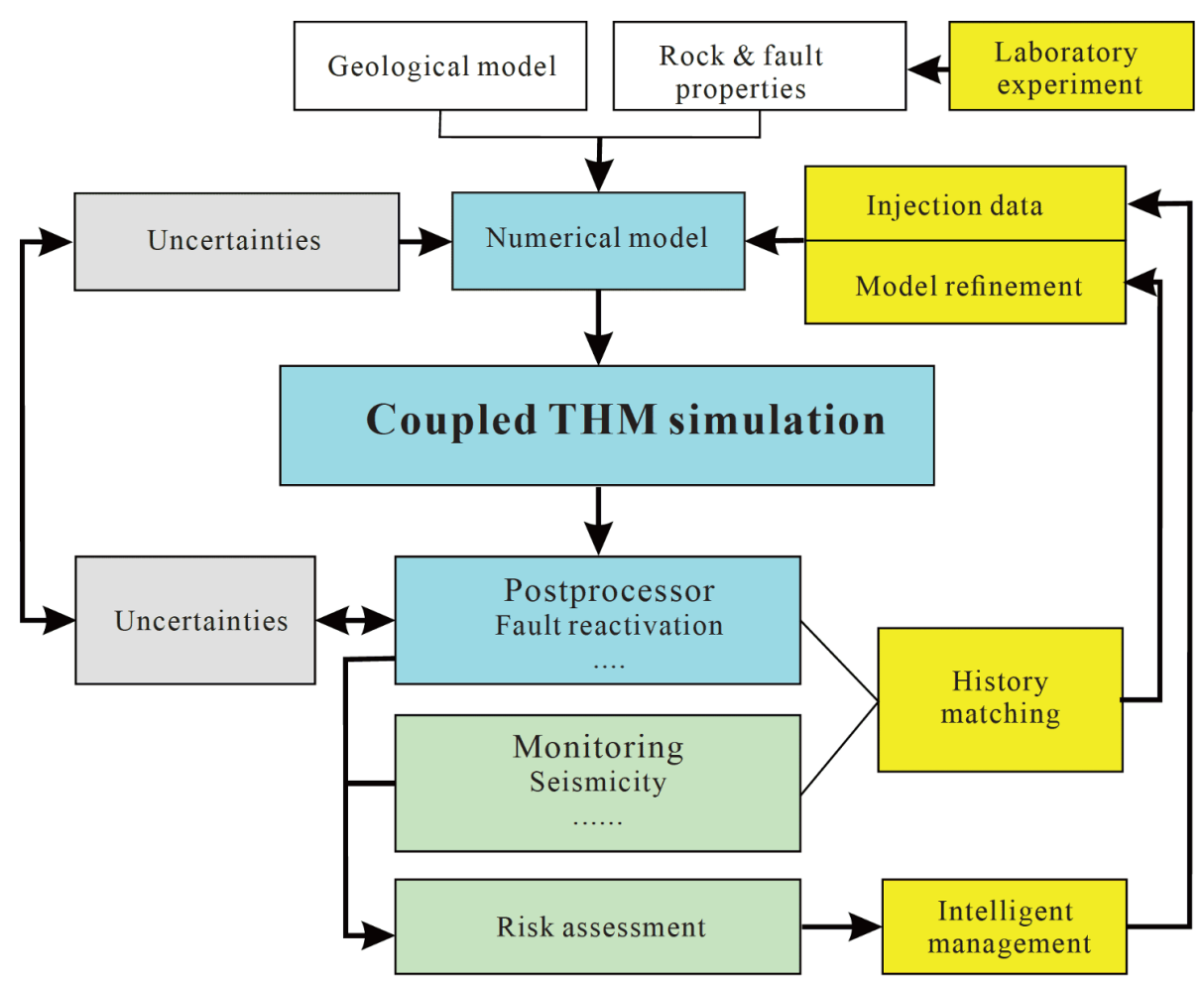

Figure 13 Flowchart of a general framework for assessment and management of risks related to induced earthquakes. See the text for details. 
based prediction. Finally, postprocessing is used to convert changes in pressure, temperature, stress, and strain into changes in observable geophysical properties and fault slip tendency. Assessment of risks associated with induced earthquakes is then made for screening and management purposes. During injection operation, history matching is applied to refine the numerical model of a reservoir to reproduce the observed data and repeat the process of risk assessment and management. An advanced traffic light system for induced seismicity should be designed as part of this management process. Detailed monitoring is helpful for building a better model and making more precise predictions.

Significant seismicity and destructive earthquakes, some likely induced by injection, have been observed in the Sichuan Basin. The observed seismic data, together with detailed injection data and 3D geological data, should be fully studied to develop advanced effective risk management techniques and ensure that shale gas fracturing can be carried out effectively and safely. Taking these points into consideration, it would be beneficial for the academic, oil industry, and regulatory communities to work collectively to elucidate the governing factors behind the high level of injection-induced seismicity in the south Sichuan Basin, thereby allowing resource extraction, such shale gas development and salt mining, to be conducted effectively and safely. To accomplish this, national regulations should be updated with the requirement for operators to take action if signs of fault reactivation are detected from either observation or numerical results.

Acknowledgements We thank three anonymous reviewers and associate editor Prof. Jing LIU-ZENG for their constructive and timely review comments. Wang acknowledges the support of the State Scholarship Fund of China (Grant No. 201804190004).

\section{References}

Ader T J, Avouac J P. 2013. Detecting periodicities and declustering in earthquake catalogs using the Schuster spectrum, application to Himalayan seismicity. Earth Planet Sci Lett, 377-378: 97-105

Ahmad M U, Smith J A. 1988. Earthquakes, injection wells, and the Perry nuclear power plant, Cleveland, Ohio. Geology, 16: 739-742

Atkinson G M, Eaton D W, Ghofrani H, Walker D, Cheadle B, Schultz R, Shcherbakov R, Tiampo K, Gu J, Harrington R M, Liu Y, van der Baan M, Kao H. 2016. Hydraulic fracturing and seismicity in the western Canada sedimentary basin. Seismol Res Lett, 87: 631-647

Bachmann C E, Wiemer S, Woessner J, Hainzl S. 2011. Statistical analysis of the induced Basel 2006 earthquake sequence: Introducing a probability-based monitoring approach for Enhanced Geothermal Systems. Geophys J Int, 186: 793-807

Båth M. 1965. Lateral inhomogeneities of the upper mantle. Tectonophysics, 2: 483-514

Chen H, Meng X, Niu F, Tang Y, Yin C, Wu F. 2018. Microseismic monitoring of stimulating shale gas reservoir in SW China: 2. Spatial clustering controlled by the preexisting faults and fractures. J Geophys Res-Solid Earth, 123: 1659-1672

China Oil and Gas Field Development Chronicle Compilation Committee. 2011. China Oil and Gas Field Development Chronicle: Southwest
China Petroleum Oil and Gas Field Volume. Beijing Petroleum Industry Press

Deng Q, Ran Y, Yang X, Min W, Chu Q. 2007. Map of Active Tectonics in China. Beijing: Seismological Press

Ding R, Li K C, eds. 2004. Seismological Research in Chongqing (in Chinese). Beijing: Seismological Press

Du F, Wu J, Li G, Guan Z, Wu X. 2002. Yibin earthquake of $M_{\mathrm{S}} 5.4$ on Feb. 28, 1996 in Sichuan Province. In: Chen Q, Deng D, Liu G, Li M, eds. Earthquake Cases in China (1995-1996) (in Chinese). Beijing: Seismological Press

Editor-Group-of-Compiling-of-Sichuan-Earthquake-Data. 1980. Compiling of Sichuan Earthquake Data. Chengdu: People's Publishing House of Sichuan

Ellsworth W L. 2013. Injection-induced earthquakes. Science, 341: 1225942

Ellsworth W L, Giardini D, Townend J, Ge S, Shimamoto T. 2019. Triggering of the Pohang, Korea, earthquake $\left(M_{\mathrm{W}} 5.5\right)$ by enhanced geothermal system stimulation. Seismol Res Lett, 90: 1844-1858

van der Elst N J, Page M T, Weiser D A, Goebel T H W, Hosseini S M. 2016. Induced earthquake magnitudes are as large as (statistically) expected. J Geophys Res-Solid Earth, 121: 4575-4590

Etchecopar A, Vasseur G, Daignieres M. 1981. An inverse problem in microtectonics for the determination of stress tensors from fault striation analysis. J Struct Geol, 3: 51-65

Eyre T S, Eaton D W, Zecevic M, D'Amico D, Kolos D. 2019. Microseismicity reveals fault activation before $M_{\mathrm{W}} 4.1$ hydraulic-fracturing induced earthquake. Geophys J Int, 218: 534-546

Gan W, Zhang P, Shen Z K, Niu Z, Wang M, Wan Y, Zhou D, Cheng J. 2007. Present-day crustal motion within the Tibetan Plateau inferred from GPS measurements. J Geophys Res, 112: B08416

Gephart J W, Forsyth D W. 1984. An improved method for determining the regional stress tensor using earthquake focal mechanism data: Application to the San Fernando earthquake sequence. J Geophys Res, 89: 9305-9320

Ghofrani H, Atkinson G M. 2016. A preliminary statistical model for hydraulic fracture-induced seismicity in the Western Canada Sedimentary Basin. Geophys Res Lett, 43: 10164-10172

Guo X, Wang X L, Zhou Y X, Gou X W, Zhang Y M. 2014. Inverting moment tensor solution of Shizhu $M_{\mathrm{S}} 4.3$ earthquake based on CAP method. Seismol Geomag Observ Res, 35: 32-37

Kanamori H, Hauksson E. 1992. A slow earthquake in the Santa Maria Basin, California. Bull Seismol Soc Am, 82: 2087-2096

Kerr R A. 2012. Learning how to not make your own earthquakes. Science, 335: 1436-1437

Kim K H, Ree J H, Kim Y H, Kim S, Kang S Y, Seo W. 2018. Assessing whether the $2017 M_{\mathrm{W}} 5.4$ Pohang earthquake in South Korea was an induced event. Science, 360: 1007-1009

Kolawole F, Johnston C S, Morgan C B, Chang J C, Marfurt K J, Lockner D A, Reches Z, Carpenter B M. 2019. The susceptibility of Oklahoma's basement to seismic reactivation. Nat Geosci, 12: 839-844

Korsch R, Huazhao M, Zhaocai S, Gorter J. 1991. The Sichuan basin, southwest China: A late proterozoic (Sinian) petroleum province. Precambrian Res, 54: 45-63

Kozłowska M, Brudzinski M R, Friberg P, Skoumal R J, Baxter N D, Currie B S. 2018. Maturity of nearby faults influences seismic hazard from hydraulic fracturing. Proc Natl Acad Sci USA, 115: E1720-E1729

Kwiatek G, Saarno T, Ader T, Bluemle F, Bohnhoff M, Chendorain M, Dresen G, Heikkinen P, Kukkonen I, Leary P, Leonhardt M, Malin P, Martínez-Garzón P, Passmore K, Passmore P, Valenzuela S, Wollin C. 2019. Controlling fluid-induced seismicity during a 6.1-km-deep geothermal stimulation in Finland. Sci Adv, 5: eaav7224

Langenbruch C, Ellsworth W L, Woo J U, Wald D J. 2020. Value at Induced Risk: Injection-induced seismic risk from low-probability, high-impact events. Geophys Res Lett, 47: e85878

Lei X, Huang D, Su J, Jiang G, Wang X, Wang H, Guo X, Fu H. 2017a. Fault reactivation and earthquakes with magnitudes of up to $M_{\mathrm{W}} 4.7$ induced by shale-gas hydraulic fracturing in Sichuan Basin, China. Sci 
Rep, 7: 7971

Lei X, Ma S, Chen W, Pang C, Zeng J, Jiang B. 2013. A detailed view of the injection-induced seismicity in a natural gas reservoir in Zigong, southwestern Sichuan Basin, China. J Geophys Res-Solid Earth, 118: 4296-4311

Lei X, Ma S, Wang X, Su J. 2017b. Fault-valve behaviour and episodic gas flow in overpressured aquifers-evidence from the $2010 M_{\mathrm{S}} 5.1$ isolated shallow earthquake in Sichuan Basin, China. Prog Comput Fluid Dyn, 17: 2

Lei X, Wang Z, Su J. 2019a. The December $2018 M_{\mathrm{L}} 5.7$ and January 2019 $M_{\mathrm{L}} 5.3$ earthquakes in South Sichuan Basin induced by shale gas hydraulic fracturing. Seismol Res Lett, 90: 1099-1110

Lei X L, Wang Z W, Su J R. 2019b. Possible link between long-term and short-term water injections and earthquakes in salt mine and shale gas site in Changning, south Sichuan Basin, China. Earth Planet Phys, 3: $510-525$

Lei X, Yu G, Ma S, Wen X, Wang Q. 2008. Earthquakes induced by water injection at $\sim 3 \mathrm{~km}$ depth within the Rongchang gas field, Chongqing, China. J Geophys Res, 113: B10310

Li Z G, Jia D, Chen W. 2013. Structural geometry and deformation mechanism of the Longquan anticline in the Longmen Shan fold-and-thrust belt, eastern Tibet. J Asian Earth Sci, 64: 223-234

Liu J, Zahradník J. 2020. The $2019 M_{\mathrm{W}} 5.7$ Changning earthquake, Sichuan Basin, China: A shallow doublet with different faulting styles. Geophys Res Lett, 47: e85408

Liu L, Liang B, Yang Z, Ying L, Yang P, Yang Y. 2019. Soil gas radon amd fault activity in the Longmenshan fault zone, Sichuan (in Chinese with English abstract). Sediment Geol Tethyan Geol, 39: 45-53

Luo Y, Ni S D, Zeng X F, Xie J, Chen Y, Long F. 2011. The M5.0 SuiningTongnan (China) earthquake of 31 January 2010: A destructive earthquake occurring in sedimentary cover. Chin Sci Bull, 56: 521-525

Lv G, Peng Y, Gao F. 2009. Progresses of the study on induced earthquake and its countermeasure project in Leshan city (in Chinese with English abstract). Recebt Develop World Seismol, (2): 19-22

Majer E L, Peterson J E. 2007. The impact of injection on seismicity at The geysers, California Geothermal field. Int J Rock Mech Min Sci, 44: 1079-1090

Mayerhofer M J, Lolon E, Warpinski N R, Cipolla C L, Walser D W, Rightmire C M. 2010. What is stimulated reservoir volume? SPE Prod Operat, 25: 89-98

McGarr A, Simpson D, Seeber L, Lee W. 2002. Case histories of induced and triggered seismicity. Inter Geophys Ser, 81: 647-664

Meng L, McGarr A, Zhou L, Zang Y. 2019. An investigation of seismicity induced by hydraulic fracturing in the Sichuan basin of China based on data from a temporary seismic network. Bull Seismol Soc Am, 109: 348-357

Morris A, Ferrill D A, Brent Henderson D B. 1996. Slip-tendency analysis and fault reactivation. Geology, 24: 275

Norbeck J H, Rubinstein J L. 2018. Hydromechanical earthquake nucleation model forecasts onset, peak, and falling rates of induced seismicity in Oklahoma and Kansas. Geophys Res Lett, 45: 2963-2975

Qian Y, Chen X, Luo H, Wei S, Wang T, Zhang Z, Luo X. 2019. An extremely shallow $M_{W} 4.1$ thrust earthquake in the Eastern Sichuan Basin (China) likely triggered by unloading during infrastructure construction. Geophys Res Lett, 46: 13775-13784

Radiguet M, Cotton F, Manighetti I, Campillo M, Douglas J. 2009. Dependency of near-field ground motions on the structural maturity of the ruptured faults. Bull Seismol Soc Am, 99: 2572-2581

Ruan X, Cheng W Z, Zhang Y J, Li J, Chen Y. 2008. Research of the earthquakes induced by water injections in salt mines in Changning (in Chinese). Earthq Res China, 24: 226-234

Rutqvist J, Rinaldi A P, Cappa F, Moridis G J. 2015. Modeling of fault activation and seismicity by injection directly into a fault zone associated with hydraulic fracturing of shale-gas reservoirs. J Pet Sci Eng, 127: $377-386$

Ryder R, Rice D, Sun Z, Zhang Y, Qiu Y, Guo Z. 1994. Petroleum geology of the Sichuan basin, China: Report on US Geological Survey and
Chinese Ministry of Geology and Mineral Resources field investigations and meetings. Report. US Geological Survey, doi: 10.3133/ ofr94426

Skoumal R J, Ries R, Brudzinski M R, Barbour A J, Currie B S. 2018. Earthquakes induced by hydraulic fracturing are pervasive in Oklahoma. J Geophys Res-Solid Earth, 123: 10918-10935

Streit J E, Hillis R R. 2004. Estimating fault stability and sustainable fluid pressures for underground storage of $\mathrm{CO}_{2}$ in porous rock. Energy, 29: $1445-1456$

Su P, Liao J, Wang Q, Wen L. 2014. Harm to tunnel engineering due to gas in shallow oil-gas structures at Longquan mountains (in Chinese with English abstract). J Eng Geol, 22: 1287-1293

Sun X, Yang P, Zhang Z. 2017. A study of earthquakes induced by water injection in the Changning salt mine area, SW China. J Asian Earth Sci, 136: $102-109$

Tan Y, Hu J, Zhang H, Chen Y, Qian J, Wang Q, Zha H, Tang P, Nie Z. 2020. Hydraulic fracturing induced seismicity in the Southern Sichuan Basin due to fluid diffusion inferred from seismic and injection data analysis. Geophys Res Lett, 47: e84885

Waldhauser F, Ellsworth W L. 2000. A double-difference earthquake location algorithm: Method and application to the northern Hayward fault, California. Bull Seismol Soc Am, 90: 1353-1368

Wang H C, Wang Z J, Yin G M, Qin J. 2009. Quaternary activity and potential earthquake ability of Changling-banbianshan fault zones in Chongqing City (in Chinese with English abstract). Earthq Res Sichuan, 4: $42-45$

Wang M, Shen Z K. 2020. Present-day crustal deformation of continental China derived from GPS and its tectonic implications. J Geophys ResSolid Earth, 125: e18774

Wang W M, Zhao L F, Li J, Yao Z X. 2008. Rupture process of the $M_{\mathrm{S}} 8.0$ Wenchuan earthquake of Sichuan, China (in Chinese). Chin J Geophys, 51: $1403-1410$

Wang X, Ma S, Guo Z, Lei X, Xia Y, Guo X, Yu G, Gou X, Jiang X. 2013. S-wave velocity of the crust in Three Gorges Reservoir and the adjacent region inverted from seismic ambient noise tomography (in Chinese with English abstract). Chin J Geophys, 56: 1-11

Wang Y, Huang J, Wang S, Dong D, Zhang C, Guan Q. 2016. Dissection of two calibrated areas of the Silurian Longmaxi Formation, Changning and Jiaoshiba, Sichuan Basin (in Chinese). Nat Gas Geosci, 27: 423432

Wang Z, Wang X, Ma S, Lei X, Liu P. 2018. Detailed temporal-spatial distribution of induced earthquakes by water injection in Rochang, Chongqiong (in Chinese with English abstract). Seismol Geol, 40: 523538

Wei H, Liu G. 2014. Study of relationship between characteristics of seismic activity and deep-well injection at Rongchang county of Chongqing Municipality (in Chinese with English abstract). Seismol Geomag Observat Res, 35: 187-191

Xu S, Ren H, Song J. 2006. Primary study on the seismicity along the faults of Longquanshan (in Chinese with English abstract). Earthq Res Sichuan, 2: 21-27

Yang H F, Liu Y J, Wei M, Zhuang J C, Zhou S Y. 2017. Induced earthquakes in the development of unconventional energy resources. Sci China Earth Sci, 60: 1632-1644

Yi G, Long F, Liang M, Zhao M, Wang S, Gong Y, Qiao H, Su J. 2019. Focal mechanism and seismogenic structure of the 17 June $2019 M_{\mathrm{S}} 6.0$ Sichuan Changning earthquake sequence (in Chinese with English abstract). Chin J Geophys, 62: 3432-3447

Zhang B, Chen R, Li H, Qi Y, Mao J, Liu P, Li F. 1993. Correlation between seismicity and water injection in Ziliujing anticline (in Chinese). Acta Seismol Sin, 5: 253-256

Zhang Z, Cheng W, Liang M, Wang X, Long F, Xu Y, Chen W, Wang S. 2012. Study on earthquakes induced by water injection in ZigongLongchang area, Sichuan (in Chinese). Chin J Geophys, 55: 16351645

Zhao X, Yang Y. 2015. The current situation of shale gas in Sichuan, China. Renew Sustain Energy Rev, 50: 653-664 
Zheng G, Wang H, Wright T J, Lou Y, Zhang R, Zhang W, Shi C, Huang J, Wei N. 2017. Crustal deformation in the India-Eurasia collision zone from 25 years of GPS measurements. J Geophys Res-Solid Earth, 122: 9290-9312

Zhu L, Ben-Zion Y. 2013. Parametrization of general seismic potency and moment tensors for source inversion of seismic waveform data. Geophys J Int, 194: 839-843
Zhu L, Helmberger D V. 1996. Advancement in source estimation techniques using broadband regional seismograms. Bull Seismol Soc Am, 86: $1634-1641$

Zou C, Dong D, Wang Y, Li X, Huang J, Wang S, Guan Q, Zhang C, Wang H, Liu H, Bai W, Liang F, Lin W, Zhao Q, Liu D, Yang Z, Liang P, Sun S, Qiu Z. 2015. Shale gas in China: Characteristics, challenges and prospects (I). Pet Explor Dev, 42: 753-767

(Responsible editor: Jing LIU-ZENG) 